\title{
Characterization of Gas Adsorption Sites and Behaviors in Metal-Organic Frameworks
}

\author{
Xiao-Jing Hu, ${ }^{\dagger, a}$ Xuan Wang, ${ }^{\dagger, b}$ Ying-Pin Chen, ${ }^{, c}$ Da-Huan Liu, ${ }^{d}$ and Tian-Fu Liu ${ }^{a}$ \\ a State Key Laboratory of Structural Chemistry, Fujian Institute of Research on the Structure of Matter, \\ Chinese Academy of Sciences, Fuzhou, Fujian 350002, China \\ ${ }^{b}$ Colorado State University-Pueblo, Pueblo, Colorado 81001, the United States \\ ${ }^{c}$ Department of Protein Purification, BioNova Scientific Inc., Fremont, California 94539, the United States \\ ${ }^{d}$ State Key Laboratory of Organic-Inorganic Composites, Beijing University of Chemical Technology, \\ Beijing 100029, China \\ Email: ying-pin.chen@chem.tamu.edu (Y. P. C.)
}

\begin{abstract}
In this paper, we start with a short introduction to the research background of gas adsorption in the metal-organic frameworks (MOFs) field, and then we highlight the gas adsorption sites and behaviors with the aid of various characterization methods, among which we discuss mainly infrared absorption and Raman scattering, as well as X-ray diffraction and neutron diffraction. In addition, we introduce briefly X-ray spectroscopy because they also play a crucial role in understanding MOFs' gas adsorption. On the other hand, computational simulations, which can reveal underlying adsorption and working mechanism in microscale, are also discussed. Finally, comprehensive kinetic studies are briefly summarized based on these advanced characterization methods.
\end{abstract}

Keywords metal-organic frameworks, gas storage, characterization methods

\section{Introduction}

Metal-organic frameworks (MOFs) are crystalline networks constructed from metal clusters/ions and organic linkers through self-assembled process. The permanent porosity, high surface area and tailorable structures are the signatures that provide MOFs with great potential in gas storage and separations in terms of energy and transport efficiency, which have been the primary focuses in research fields and widely studied for MOFs' applications. ${ }^{[1-3]}$ MOFs, which could be dated back to $1990 \mathrm{~s},{ }^{[4]}$ have been potentially applicable in luminescence, catalysis, gas storage and separation, and so on. ${ }^{[5-8]}$ The hallmark of MOFs is superior surface areas with adjustable pore sizes, which simulate the development of applications in sustainable energy-related gas storage and separation. Rational design of frameworks with high storage capacity or separation becomes a mainstream in the past twenty years. As a result, hundreds of MOFs have been developed for gas storage or separation, in particular for hydrogen, ${ }^{[9-12]}$ methane,$^{[5,13-17]}$ and carbon dioxide. ${ }^{[18-23]}$ For instance, one of the best materials for methane storage is HKUST-1 (HKUST=Hong Kong University of Science and Technology), ${ }^{[13]}$ which exhibited a total volumetric capacity of $230 \mathrm{cc}(\mathrm{STP}) / \mathrm{cc}$ and $270 \mathrm{cc}(\mathrm{STP}) / \mathrm{cc}$ (STP: standard temperature and pressure, $273.15 \mathrm{~K}, 1 \mathrm{~atm}$ ) at 35 and $65 \mathrm{bar}$, respectively, with a working capacity of $190 \mathrm{cc}$ (STP)/cc in a recent report, which turns out good for commercialization in powering auto vehicles. Nowadays, it becomes commercial available. ${ }^{[24]}$ However, the industrial application of those MOFs stalls due to the their easy poisoning by sulfur oxides among the natural gas pipelines and as well as packing problems. ${ }^{[16]}$ Therefore, studying the detailed gas adsorption process in order to ultimately design new MOFs with better stability and higher gas uptake properties is in great demand. ${ }^{[25]}$ Nevertheless, such studies are quite scarce due to the lack of attention. ${ }^{[26]}$ Considering the interactions between MOFs and guest molecules play a key role in gas storage and separation, we aim to review briefly recent discoveries about interactions between MOFs and gaseous guests with the expectation to benefit future design that meet the commercial application. Herein, studies about various characterization methods for MOFs' gas sorption properties, including infrared absorption and Raman scattering, X-ray diffraction, neutron diffraction, and X-ray spectroscopy, and computational simulations will be outlined. At the end, comprehensive kinetic studies will be further highlighted.

\section{Infrared absorption and Raman scattering}

The major interactions between MOFs and gas molecules are electrostatic interactions and van der Waals (vdW) forces. As the experimental studies on those interactions rely highly on the bonding configurations of guest molecules within the framework, it could be generally characterized by the vibrational spectroscopy, such as IR adsorption and Raman scattering. ${ }^{[27,28]}$ In this section, we will focus on using IR and Raman to probe the interactions between guest molecules and surface of MOFs. Studies about the vibrational changes in the adsorption studies of $\mathrm{H}_{2},{ }^{[29-31]} \mathrm{SO}_{2},{ }^{[32]} \mathrm{CH}_{4},{ }^{[33]} \mathrm{CO}^{\left[{ }^{[34-37]}\right.}$ and $\mathrm{CO}_{2}{ }^{[38-43]}$ using IR absorption and Raman scattering will be discussed.

\section{Infrared absorption spectroscopy (IR)}

The vibrational frequency of bonding of guests or frameworks always shifts during the kinetically diffusion and adsorption process. In this regard, those shifts could be clearly observed using IR absorption spectroscopy. Taking $\mathrm{CO}_{2}$ as an 


\section{Review}

example, the linear molecule has four vibrational normal modes but three fundamental vibration frequencies due to the degeneracy of two bending modes (Figure 1). ${ }^{[44,45]}$ In the adsorption process of $\mathrm{CO}_{2}$ within MOFs, both the bending $v_{2}$ and asymmetric stretching $U_{3}$ modes of $\mathrm{CO}_{2}$ are perturbed when interacting with framework, which change usually the dipole moment and consequently gives rise to the frequency shifts in the IR spectra. Meanwhile, the symmetric stretching $v_{1}$ of $\mathrm{CO}_{2}$ becomes Raman active due to the altered polarizability. ${ }^{[45]}$ In the following examples, studies using IR absorption spectroscopy will be outlined based on the different causes-structural change of MOFs, functionalization on organic linkers and direct influence from metal secondary building units (SBUs).

\section{Structural change of MOFs}

Vimont and coworkers ${ }^{[38]}$ reported that the carbon atom of $\mathrm{CO}_{2}$ interacts with the oxygen atoms of hydroxyl groups in MIL-53(Cr) as an electron-acceptor with the spectroscopic evidence for formation of electron-donor-cceptor (EDA) Complex between the $\mathrm{CO}_{2}$ and hydroxyl group in framework. The IR spectra of MIL-53(Cr) demonstrated a redshift of the $v_{3}$ band (from 2335 to $2349 \mathrm{~cm}^{-1}$ with increasing amount of $\mathrm{CO}_{2}$. A splitting of $U_{2}$ mode $\left(662\right.$ and $650 \mathrm{~cm}^{-1}$ ) was also observed due to the symmetry lowering of the absorbed $\mathrm{CO}_{2}$ (Figure 2). Along with a significant perturbation for the corresponding IR band of $\mu-\mathrm{OH}$ of the oxo-chromium (III) SBUs, the authors ascribed the splitting to the interactions between the oxygen of $\mu-\mathrm{OH}$ and carbon atom of $\mathrm{CO}_{2}$. A similar splitting of $v_{2}$ has also been reported by Ferrey and coworkers. ${ }^{[46]}$ In addition to the $v_{2}$ splitting and the significant perturbation of the $v(\mathrm{OH})$ band, IR spectra revealed that the band at $1022 \mathrm{~cm}^{-1}$ for the dehydrated sample shifted to $1017 \mathrm{~cm}^{-1}$ under 1 bar of $\mathrm{CO}_{2}$ and progressively returned to its initial position with an increasing pressure to 10 bar during an adsorption-desorption cycle. This shift could be directly attributed to the structural changes of MIL-53 from the opening forms $\left(1022 \mathrm{~cm}^{-1}\right)$ to the closed form $\left(1017 \mathrm{~cm}^{-1}\right)$, which enabled us to evaluate the ratio of the open and closed structures upon $\mathrm{CO}_{2}$ adsorption (Figure 3). Noticeably, a new $v_{2}$ band appeared at $659 \mathrm{~cm}^{-1}$ at higher $\mathrm{CO}_{2}$ pressure, which could be a sign of a small perturbation of the hydroxyl groups caused by the opening structure. In addition to the hydroxyl groups, amine grafting has been approved to improve the $\mathrm{CO}_{2}$ capture significantly. ${ }^{[47,48]}$ Eli Stavitski and coworkers ${ }^{[39]}$ studied the $\mathrm{N}-\mathrm{H}$ stretching of $\mathrm{NH}_{2}-\mathrm{MIL}-53$ using IR. They found the $\mathrm{N}-\mathrm{H}$ stretching region was only slightly affected upon $\mathrm{CO}_{2}$ exposure, which was in contrast to the previous published result. ${ }^{[49]}$ However, it should be considered of high importance for the overall performance of the adsorbents, since full regeneration might be achieved under very mild conditions.

\section{Functionalization on organic linkers}

Functionalization on the organic likers with polar groups is another prospective method to provide extra adsorption sites for $\mathrm{CO}_{2}$. After the perturbation of polar group linker $\mathrm{Br}$ and $\mathrm{Cl}$, the perturbed $\delta(\mathrm{OH})$ at $890 \mathrm{~cm}^{-1}$ was surprisingly identical to that of free MIL-53(Fe). Since only one perturbed OH component existed in the IR spectra, the researcher concluded there was no direct interaction between the polar groups and $\mathrm{CO}_{2}$ in

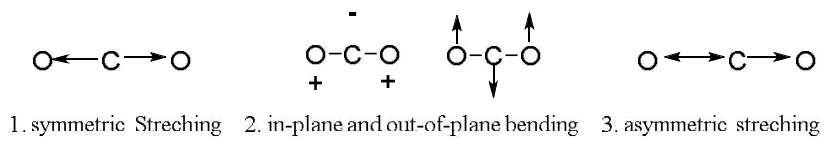

Figure 1 Three vibrational frequencies of four vibrational normal modes of $\mathrm{CO}_{2}$. Reprinted with permission from Ref. [44]. Copyright 1992 Elsevier. those cases. ${ }^{[50]}$ Moreover, the retained $\mathrm{N}-\mathrm{H}$ stretching frequency of $\mathrm{NH}_{2}-\mathrm{MIL}-53$ and the persisted $\delta(\mathrm{OH})$ of other functionalized MIL-53 implied that the polar groups tended generally to break the hydrogen bonds with the $\mu-\mathrm{OH}$ instead of direct interacting with $\mathrm{CO}_{2}$.

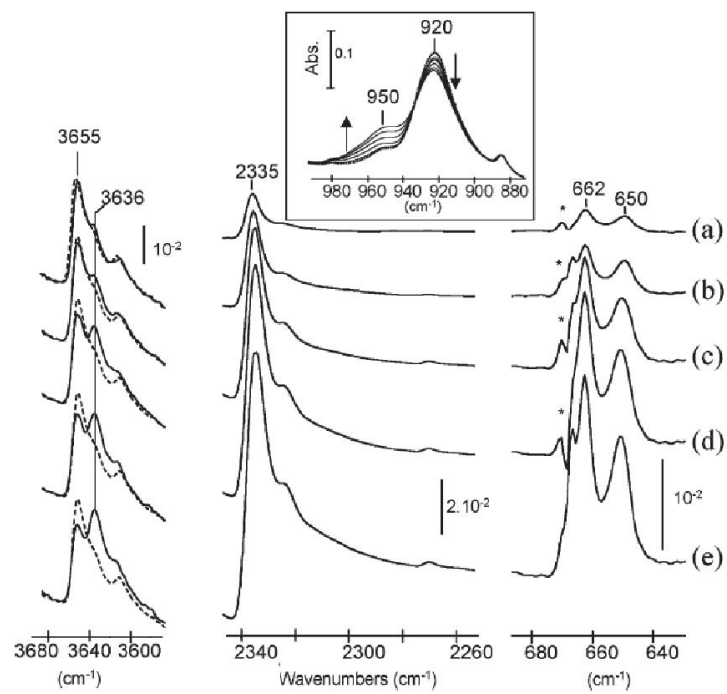

Figure 2 IR spectra of activated MIL-53(Cr) with increasing $\mathrm{CO}_{2}$ pressure to (a) $1066 \mathrm{~Pa}$, (b) $2400 \mathrm{~Pa}$, (c) $3850 \mathrm{~Pa}$, (d)5000 $\mathrm{Pa}$, e) $5850 \mathrm{~Pa}$. Inset: perturbation of $\delta(\mathrm{OH})$ mode upon adsorption. Reprinted with permission from Ref. [38]. Copyright 2007 Royal Society of Chemistry.

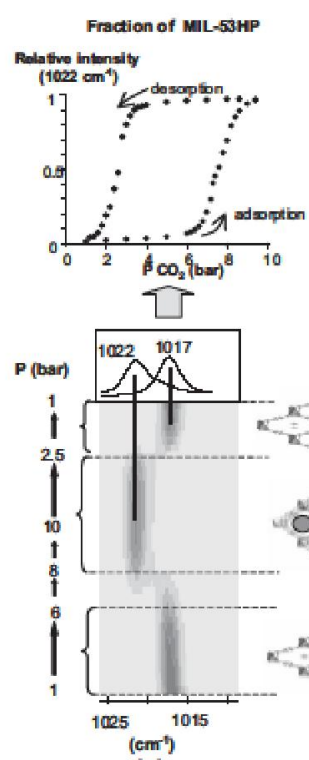

(a)
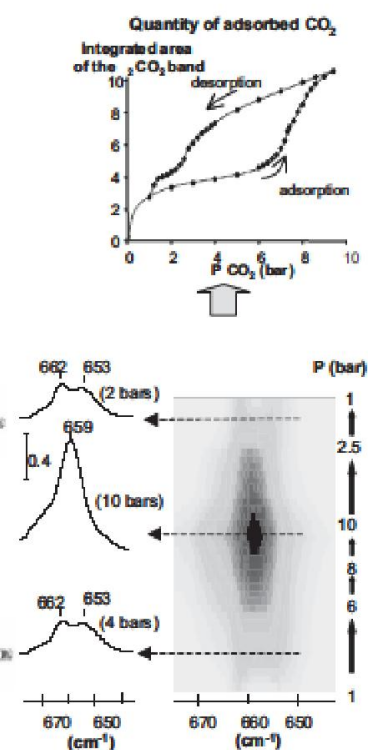

(b)
Figure 3 Bottom (2D IR Map): a) Variation in the intensities of MIL-53LP $\left(1017 \mathrm{~cm}^{-1}\right)$ and MIL-53HP $\left(1022 \mathrm{~cm}^{-1}\right)$ bands and $\left.\mathrm{b}\right)$ in the $\mathrm{v}_{2} \mathrm{CO}_{2}$ bands $\left(653,662 \mathrm{~cm}^{-1}\right.$ MIL-53LP; $659 \mathrm{~cm}^{-1}$ MIL-53HP versus $\mathrm{CO}_{2}$ pressure. Top: hysteresis phenomenon observed during an adsorption-desorption cycle. Curves were obtained from the quantitative analysis of the corresponding IR spectra. Reprinted with permission from Ref. [46]. Copyright 2007 Wiley-VCH. 


\section{General Chemistry}

\section{Open metal sites and metal centers}

The direct coordination of metals to $\mathrm{CO}_{2}$ was firstly reported on the open mental site of CPO-27, which was isostructural to MOF-74. ${ }^{[51]}$ The IR component at $2341 \mathrm{~cm}^{-1}$ with a shoulder at $2329 \mathrm{~cm}^{-1}$ significantly increased upon a progressive decreased $\mathrm{CO}_{2}$ pressure, which corresponded to a perturbed $v_{3}$ mode with formation of $\mathrm{Ni}^{2+} \cdots \mathrm{O}=\mathrm{C}=\mathrm{O}$ adducts (Figure 4). Meanwhile, the $U_{2}$ mode of $\mathrm{CO}_{2}$ was also perturbed in the evidence of an intense doublet at 659 and $651 \mathrm{~cm}^{-1}$. Similar perturbations on $v_{2}$ and $v_{3}$ modes were also noticeable in the series of $\mathrm{M}(\mathrm{II})-\mathrm{MOF}-74$ (M = Mg, Zn, Co, Ni). ${ }^{[52]}$ Interestingly, the open $\mathrm{Zn}$ centers had the strongest redshift influence on the $v_{3}$ frequency, while the Mg center had almost no effect. In this case, it could be summarized that the interactions between the adsorbed $\mathrm{CO}_{2}$ and the $3 \mathrm{~d}$ electrons led to the different $v_{3}$ frequency.

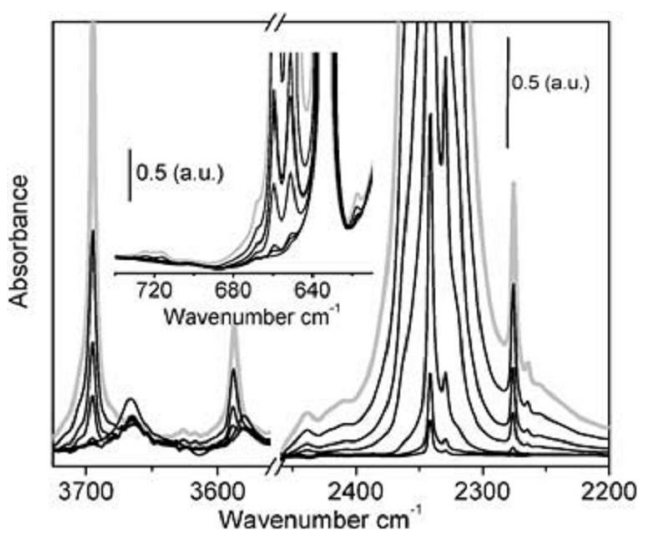

Figure 4 Spectra of $\mathrm{CPO}-27-\mathrm{Ni}$ at decreasing $\mathrm{CO}_{2}$ pressure. Inset: the $\mathrm{CO}_{2}$ bending region. Reprinted with permission from Ref. [51]. Copyright 2008 Royal Society of Chemistry.

\section{Raman scattering}

In the same manner of IR absorption spectra, Raman scattering also provides detailed information on the bond breaking and formation during the adsorption process. Herein, we will discuss a typical case study for water adsorption. In the examination of moisture stability of a series of paddle wheel-based frameworks $\mathrm{M}(\mathrm{bdc})(\mathrm{ted})_{0.5}(\mathrm{M}=\mathrm{Cu}, \mathrm{Co}, \mathrm{Ni}, \mathrm{Zn}$; $\mathrm{H}_{2} \mathrm{bdc}=1,4$-bezenedicarboxylate; ted = triethylenedia mine), Chabal and coworkers ${ }^{[53]}$ noticed significant changes of two Raman bands (Figure 5). One Raman band was associated with the mixing of the lone pair of the nitrogen with the $\mathrm{C}-\mathrm{C}$ of the organic linkers $\left(v_{4}\right)$, and the other band was associated with the metal-metal interaction in the paddle wheels. Although the activated MOFs all adopted the signature IR frequency bands, distinct Raman bands were observed upon hydration. The $v_{4}$ band persisted in case of the $\mathrm{Cu}-$, Co-, and Ni-based MOFs, while a redshift occurred in the $\mathrm{Zn}$-based MOF due to the dissociation of nitrogen of the ted linkers from the $\mathrm{Zn}$ cluster. Furthermore, the metal-metal vibration was highly metal-dependent, as it persisted in the Ni-based MOF, vanished in the Zn-based MOF, combined to a single band with a new band at $268 \mathrm{~cm}^{-1}$ in the Cu-based MOF, or completely disappeared in the Co-based MOF. All the Raman shifts provided direct evidence of the critical dependence of the moisture stability on the metal ions in this isostructural MOFs.

\section{X-ray diffraction}

\section{Single Crystal X-ray Diffraction (SCXRD)}

Among all the characterization methods in the sorption study of MOFs, SCXRD can provide direct visualization of MOF-guest interactions. ${ }^{[54]}$ Early gas sorption studies using SCXRD focused on the structural changes and the phase transitions caused by the adsorbed gas molecules. ${ }^{[36,55-57]}$ Kitagawa and coworkers ${ }^{[58]}$ reported the first observation of porous to nonporous phase transition of a flexible open framework. In their study, the 2D bilayer flexible open Cu-framework showed sponge-like dynamic behavior with bond breaking and formation triggered by hydration and dehydration. With the aid of structural determination by SCXRD, the gate-opening and gate-closing phenomenon could be directly evidenced and attributed to the MOF-guest interactions. Observations on phase transitions by SCXRD were also noted by the Moggach's group ${ }^{[59]}$ the Takamizawa's group, ${ }^{[60]}$ and the Morries's group. ${ }^{[61]}$ The guest dependence of interaction sites were later studied in details by Wright and coworkers. ${ }^{[62]}$ The measurements of adsorption of $\mathrm{CO}_{2}, \mathrm{CH}_{4}$, and $\mathrm{C}_{2} \mathrm{H}_{6}$ on a microporous MOF, ScBDC, provided the proof of well-defined and gas-specific adsorption sites. Both $\mathrm{CH}_{4}$ and $\mathrm{C}_{2} \mathrm{H}_{6}$ had similar adsorption sites in the framework channels, whereas the $\mathrm{CO}_{2}$ molecules interacted with the aromatic $\mathrm{H}$ atom of the framework in an end-on fashion along with a cavity a formation as three phenyl rings of the ligands rotated close to $\mathrm{CO}_{2}$.

Functionalization on the surface of MOFs has approved as a subject of increasing MOF-guest interaction sites. ${ }^{[23,63-67]}$ Zhang and Chen ${ }^{[68]}$ reported in situ SCXRD studies on loading $\mathrm{CO}_{2}$ into MAF-2 (MAF = metal azolate framework), a MOF of copper and 3,5-diehyl-1,2,4-triazole. The SCXRD study revealed the $\mathrm{CO}_{2}$ molecules were well embedded in the pocket
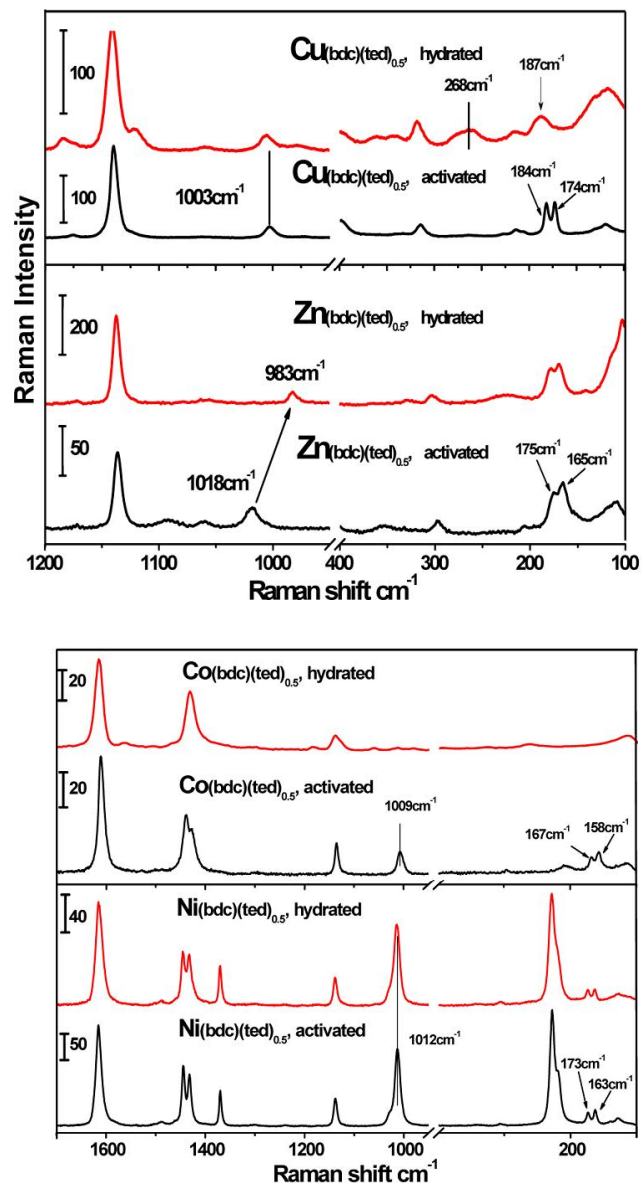

Figure 5 Raman spectra of activated MOF before and after hydration. Reprinted with permission from Ref. [53]. Copyright 2012 American Chemical Society. 


\section{Review}

with a distance of $3.41 \AA$, which were significantly larger than the van der Waals radii of $\mathrm{CO}_{2}(3.25 \AA)$, indicating the coordinated nitrogen atoms of MAF-2 served as an electronegative site (Figure 6). In another example of MAF-X $7,{ }^{[69]}$ partially coordination between triazolate nitrogen atoms and $\mathrm{CO}_{2}$ was evident by a shorter distance between the carbon of $\mathrm{CO}_{2}$ and the nitrogen of the triazolate linkers. Moreover, the $\mathrm{CO}_{2}$ molecules were also directed towards the $\mathrm{H}^{+}$cation through oxygen of DMF, and a weak hydrogen bond was formed between the pyridyl ring and a $\mathrm{CO}_{2}$ molecule. Therefore, the cooperative effect of the partially uncoordinated nitrogen, the anionic framework, the cation inside the channel, and the suitable pore size/shape all contributed to the strong $\mathrm{CO}_{2}$ binding in MAF-X7. Meanwhile, Shimizu and coworkers ${ }^{[70]}$ conducted X-ray diffraction experiments by loading $\mathrm{CO}_{2}$ into $\left[\mathrm{Zn}_{2}(\mathrm{Atz})_{2}(\mathrm{ox})\right]$, a MOF constructed from amino-functionalized 1,2,4-triazoles (Atz), oxalate ligands, and $\mathrm{Zn}$, at different temperatures. A loading of $1.2 \mathrm{CO}_{2}$ per MOF formula unit could be optimized, which was in agreement with the gravimetric adsorption measurements. SCXRD study revealed that two $\mathrm{CO}_{2}$ molecules were crystallographically located inside the pore. The distance between the carbon of $\mathrm{CO}_{2}$ molecules and the nitrogen atoms of the amino group was $3.151 \AA$, and the $\mathrm{H}$ atom of the amino group was out of the plane of the triazole (Figure 7). These two observations indicated the lone pair electrons of the nitrogen were responsible for $\mathrm{CO}_{2}$ binding. Moreover, gas adsorption study on MAF-23 exhibited an even shorter N-C distance of $3.011 \AA$, and each of the two $\mathrm{CO}_{2}$ molecules interacted simultaneously with a pair of uncoordinated $\mathrm{N}$ donor like a molecule claw. ${ }^{[71]}$ Therefore, a narrower $\mathrm{N} \cdots \mathrm{N}$ claw angle demonstrated a higher $\mathrm{CO}_{2}$ affinity.

\section{Powder X-Ray Diffraction (PXRD)}

\section{Observation of structural change}

In MOF field, there are enormous reports investigating the relationship between structural change and gas adsorption from the in situ PXRD data. ${ }^{[37,40,42,63,72-74]}$ One of the novel isostructural series, MIL-53(M(III)), possesses a pressure-responsive behavior, which is termed "breathing". ${ }^{[7]}$ This breathing phenomenon often occurs in the MOF materials possessing 1D or 2D metal moieties decorated on the structural tunnels. Férey's group had crystallographically studied the framework response in situ by synchrotron PXRD. It was found that anhydrous MIL-53(Cr) possesses a reversible cycling property upon $\mathrm{CO}_{2}$ addition ranging from 0 to 10 bar (Figure 8). ${ }^{[46]}$ The tunnel structure adopted the low-pressure form (MIL-53LP) below 4 bar, then it transformed to the high-pressure form (MIL-53HP) above 5 bar. The high-pressure form could further be converted to the low-pressure version upon $\mathrm{CO}_{2}$ exhaust with a hysteresis. This structural evolution upon $\mathrm{CO}_{2}$ loading resolved by PXRD analysis gave a visualized image of the breathing effect. Further in situ PXRD studies on MIL-53 with various metal clusters $(\mathrm{Fe}, \mathrm{Cr}, \mathrm{Al})^{[76]}$ and different functional groups $\left(-\mathrm{Cl},-\mathrm{Br},-\mathrm{CH}_{3}\right)$ were thoroughly investigated with various hydrocarbon adsorbates. ${ }^{[77,78]}$

Zhou's group ${ }^{[79]}$ published an interesting stimuli-responsive MOF, PCN-123, which possessed reversible alteration of guest molecule adsorption upon photo irradiation or thermal treatment. The working principle was to introduce a photo-sensitive functional group, azo-phenyl ring, into the organic linkers of $\mathrm{PCN}-123$. As azo-phenyl rings can switch its conformations from trans-isomer to cis by external stimulation, the resulting MOF is able to present structural change. In order to experimentally observe the structural change, envelope analysis method was applied through PXRD experiments. ${ }^{[80-82]}$ As shown in Figure 9 (Middle), the electron density difference ex-
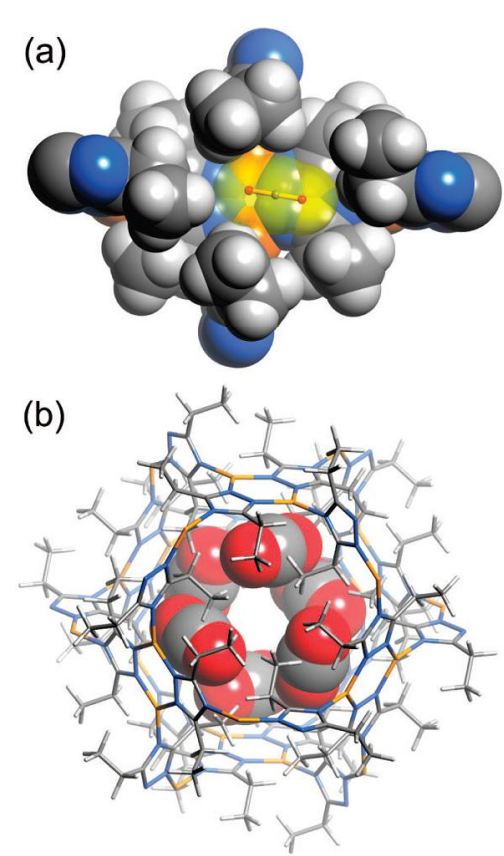

Figure $6 \quad \mathrm{~A} \mathrm{CO}_{2}$ molecule trapped inside the pocket (a) and six molecules collected in the cage (b) of MAF-2. Reprinted with permission from Ref. [68]. Copyright 2009 American Chemical Society.

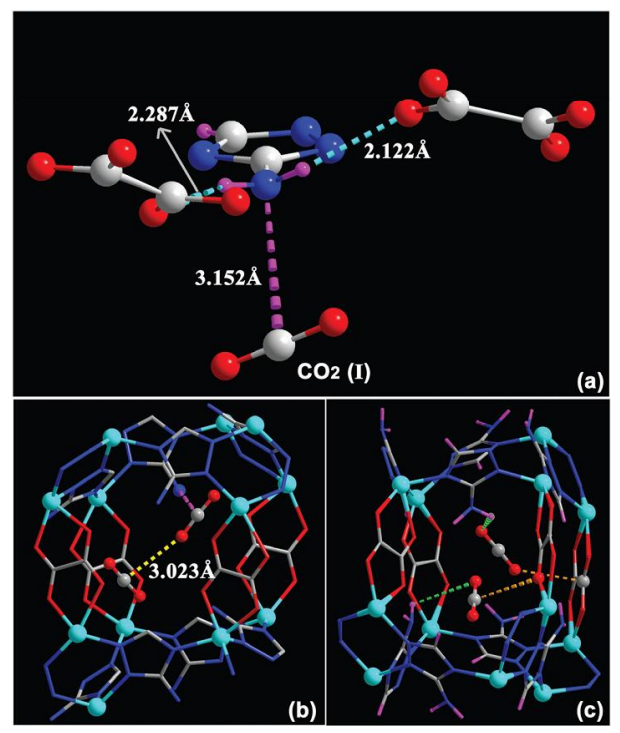

Figure $7 \quad \mathrm{CO}_{2}$ molecular binding with $\mathrm{Zn}_{2}(\mathrm{Atz})_{2}(\mathrm{ox})$ at $173 \mathrm{~K}$. Reprinted with permission from Ref. [70]. Copyright 2010 American Association for the Advancement of Science.

tracted from PXRD data corresponded to the orientation of azo-benzene groups. Before UV irradiation, it showed less electron density around the metal clusters but more nearby the ligands in the trans-isomer. In contrast, electron density around metal clusters was increased after UV irradiation. It experimentally demonstrated the flip response of azo-benzene groups with photo/heat stimulation. Besides, it could be seen that the space for $\mathrm{CO}_{2}$ molecules to adsorb was affected by the steric hindrance caused by azo-benzene groups. As a result, different amounts of $\mathrm{CO}_{2}$ molecules could be controlled by the trans/cis isomerization, as experimentally observed by the PXRD analysis. 


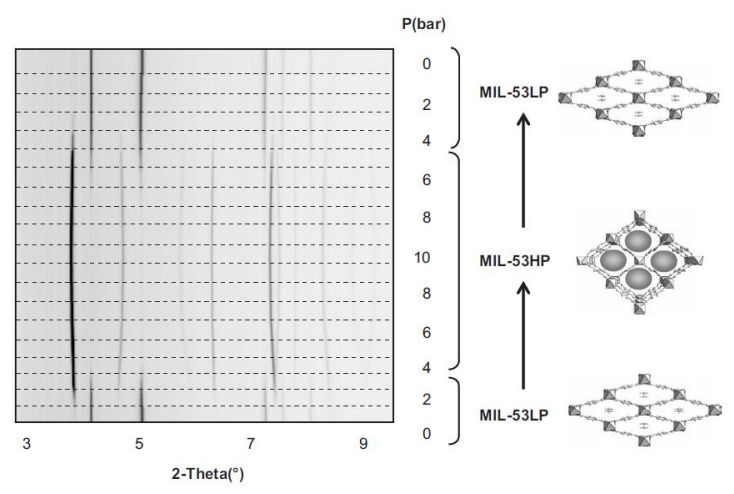

Figure 8 Left: In situ powder XRD patterns of MIL-53(Cr) collected under various pressures of $\mathrm{CO}_{2}$ at $293 \mathrm{~K}$. Right: The corresponding structural changes with $\mathrm{CO}_{2}$ pressures. Reprinted with permission from Ref. [46]. Copyright 2007 Wiley$\mathrm{VCH}$.

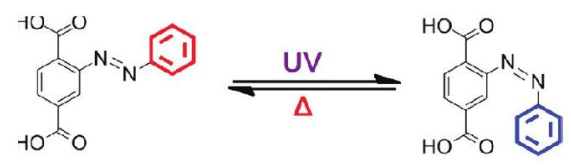

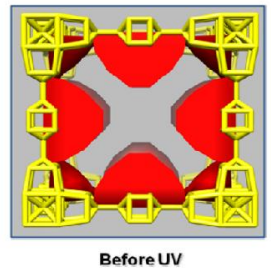

Before UV
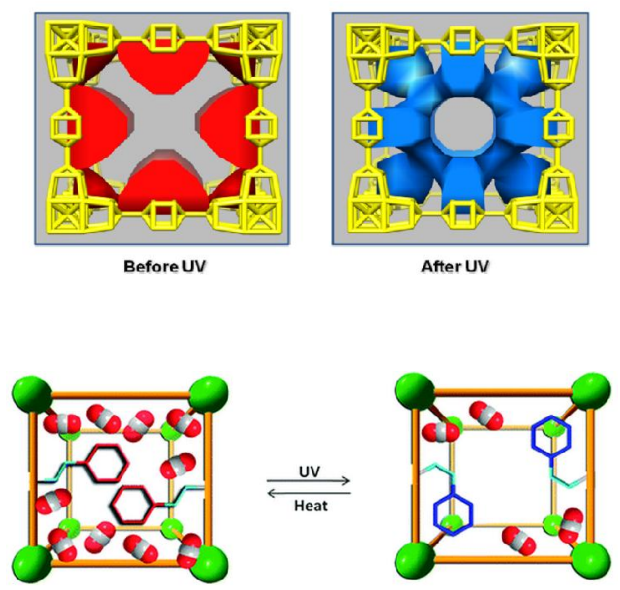

Figure 9 Top: Trans-cis isomerization of the ligand of PCN-123 induced by UV irradiation and thermal treatment reversibly. Middle: The electron density differences of PCN-123 generated from in situ powder XRD analysis. Bottom: Simulated $\mathrm{CO}_{2}$ uptake was illustrated in PCN-123-trans and PCN123-cis. Reprinted with permission from Ref. [79]. Copyright 2011 American Chemical Society.

\section{Neutron diffraction}

Neutron diffraction and X-ray diffraction differ in the way to be scattered by matters but are similar in the analytical techniques. Neutrons interact with atomic nuclei, while X-rays disturb the electron clouds of the samples. It has been understood that X-ray produces stronger interference signals when hitting atoms possessing larger electron numbers. As compared with cross sections of $X$-ray scattering, which is proportional to $Z^{2}$ ( $Z=$ atomic number), those of neutron scattering show little systematic tendency with $Z$. Moreover, neutron diffraction distinguish one element from another, and more precisely, from one isotope of an element to another as well. ${ }^{[83]}$

As complementary methods, $\mathrm{X}$-ray diffraction and neutron diffraction have different sensitivities for different elements. It has been approved that neutron diffraction is an irreplaceable tool for scientists to analyze $\mathrm{H}_{2}$ adsorption sites in the MOFs. The nuclei ${ }^{1} \mathrm{H}$ and ${ }^{2} \mathrm{H}$ are more detectable by neutron diffraction, as they are stronger scatters for neutrons. Therefore, neutron diffraction studies have been desirable to obtain accurate positions of $\mathrm{H}_{2}$, which is typically impossible using X-ray diffraction. The $\mathrm{H}$ atoms possess large incoherent scattering cross section in neutron diffraction experiments, as caused knotty difficulties in positional identification, deuterium $\left(D_{2}\right)$ has been a substituent instead. ${ }^{[63]}$

\section{Single crystal neutron diffraction (SCND)}

The first study to elucidate the hydrogen adsorption sites using single crystal neutron diffraction was reported by Spencer and coworkers. ${ }^{[84]}$ The adsorption sites were determined according to the neutron Laue data collected on MOF-5 at 120, 50, 30 , and $5 \mathrm{~K}$. The $\alpha$-sites were found over the shared vertex of $\mathrm{ZnO}_{4}$ units, which were fully occupied under 50,30 , and $5 \mathrm{~K}$ (Figure 10). Another adsorption site was located on a site of $3 \mathrm{~m}$ symmetry over the face of a $\mathrm{ZnO}_{4}$ tetrahedron at $5 \mathrm{~K}$.
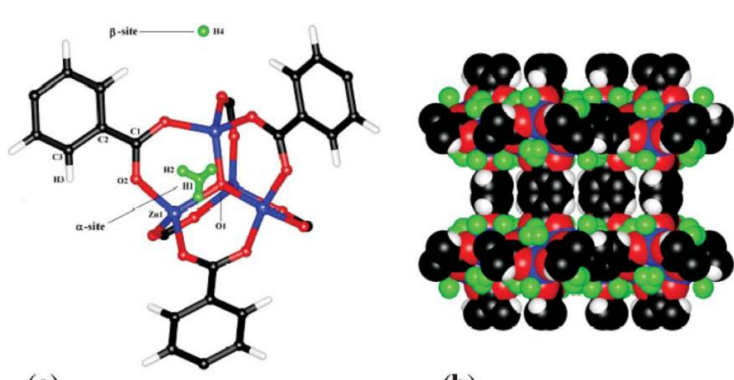

(b)

Figure 10 (a) The location of the hydrogen absorption sites at $5 \mathrm{~K}$ relative to the framework atoms. (b) Space-filling diagram of one of the framework cavities at $5 \mathrm{~K}$. Reprinted with permission from Ref. [84]. Copyright 2006 the Royal Society of Chemistry.

\section{Powder neutron diffraction (PND)}

\section{Positional identification of $\mathrm{H}_{2} / \mathrm{D}_{2}$}

Peterson and Kepert et al. ${ }^{[5,86]}$ reported six stable $\mathrm{D}_{2}$ adsorption sites in HKUST (Figure 11). They designed this in situ PND experiments by loading various volumes of $D_{2}$ into a capillary line packed with HKUST-1 at $77 \mathrm{~K}$ and then collected the PND patterns. Fourier analyses revealed that the $\mathrm{H}_{2}$ molecules initially preferred site $D_{2}(1)$, which was located at the unsaturated axial sites of the Cu paddle wheels, and then occupied $D_{2}$ (2) and $D_{2}$ (6) (top panel of Figure 11). It gave direct evidence that the Coulomb-type electrostatic interactions between the exposed metal sites and $D_{2}$ played a key role in the overall storage. Other adsorption sites were sequentially occupied with the pores size from the smallest to the largest. Remarkably, it followed concentration-dependent arrangements, which were competitively determined by $D_{2}-D_{2}$ and $D_{2}$-framework interactions (bottom panel of Figure 11).

NIST (National Institute for Standards and Technology Center for Neutron Research) had also made endeavors on a special phenomenon of hydrogen storage in MOF-5 and ZIF-8. ${ }^{[87,88]}$ Six adsorption sites were obtained from the Fourier difference analyses after Rietveld refinements in ZIF-8, while four sites were found in MOF-5 in a similar manner (Figure 12). Interestingly, it revealed that the adjacent $D_{2}$ molecules were apart with a distance of $3.0 \AA$ under low temperature and high concentration, constructing interlinked molecular nanocages. Different $D_{2}$ nanocages could be formed with distinguishable topologies by varying the $D_{2}$ loadings (Figure 13). It suggested that MOF lattices could be used as a template to build artificial 

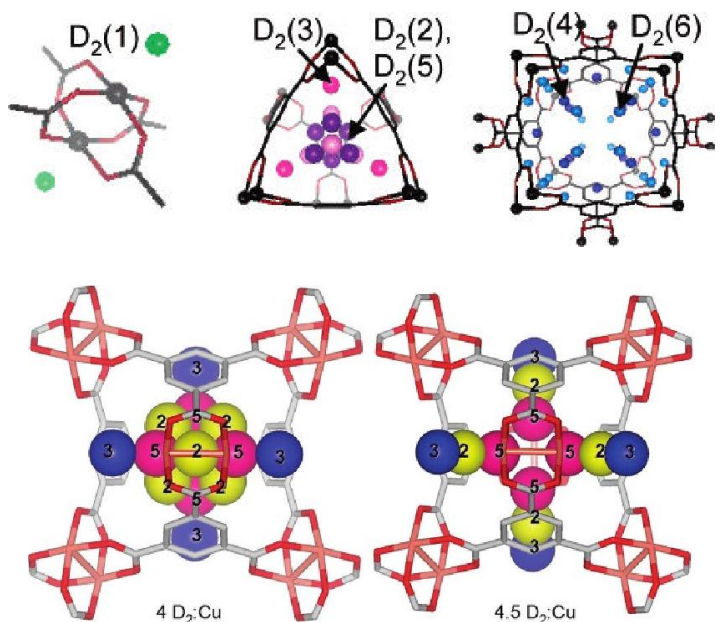

Figure $11 \quad D_{2}$ sites in HKUST-1: site 1 is the axial Cu sites; site 2, 3, 5 viewed along [111] in the small octahedral pores; site 4, 6 viewed along [100] in the large cuboctahedral cages. Reprinted with permission from Ref. [85, 86]. Copyright 2006 and 2011 American Chemical Society.
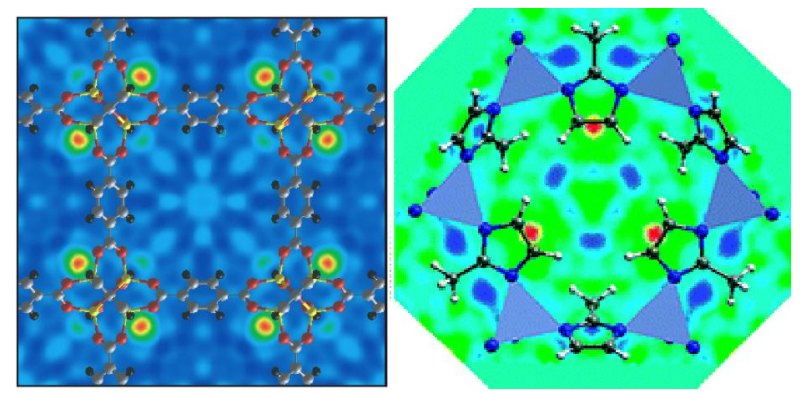

Figure 12 The real-space Fourier-difference scattering-length density superimposed with (left) the MOF-5 and (right) ZIF-8 structures. Reprinted with permission from Ref. [87, 88]. Copyright 2005 American Physical Society and 2007 American Chemical Society.

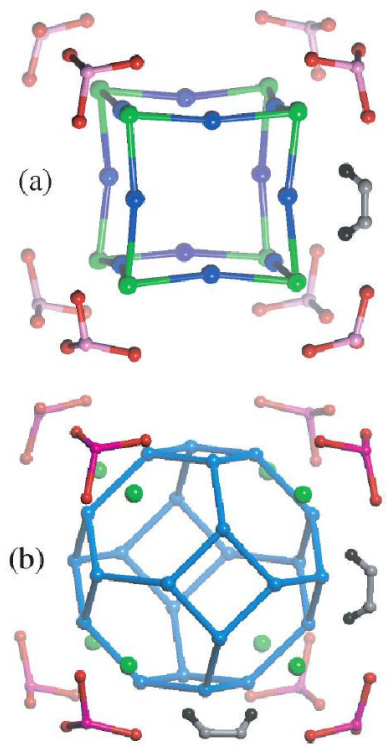

Figure 13 Different $D_{2}$ nanocages in MOF-5 (blue and green spheres) obtained at (a) 34 and (b) $46 D_{2}$ per unit loading, respectively. Reprinted with permission from Ref. [87]. Copyright 2005 American Physical Society. hydrogen nanoclusters, which might possess unique quantum natures and confinement effects. ${ }^{[87]}$ As a future perspective, it points out a direction for this important theoretical research.

Positional identification of guest molecules

Synchrotron-based or neutron-based powder diffraction is widely used for probing the favored locations of various guest molecules, including $\mathrm{CH}_{4}, \mathrm{CO}_{2}$ and noble gases. ${ }^{[67,89]}$ In this type of research, structure details can be determined by X-ray and/or neutron diffraction data, which could potentially elucidate the fundamental understanding of the adsorption mechanisms and reveal a direction towards advanced MOF designs. ${ }^{[15]}$ For instance, $\mathrm{Wu}$ and colleagues ${ }^{[90-92]}$ determined the $\mathrm{CH}_{4}$ binding sites or several prototypical MOFs. It was found that $\mathrm{CH}_{4}$ adsorption was initiated from the coulomb interactions with coordinately unsaturated metals and multiple vdW interactions with open metal sites, window openings, cage centers and cage corner sites. Bases on this study, it can be found that the accessibility and compatibility of pore volume for different guest molecules are favorable structural features for methane storage. The Hulvey's investigation of noble gases ( $\mathrm{Xe}, \mathrm{Kr}, \mathrm{Ar}, \mathrm{Ne}$ ) adsorption in HKUST-1 gave a parallel conclusion that dominant binding sites are located in and around the small tetrahedral cages instead of the open $\mathrm{Cu}(\mathrm{II})$ sites (Figure 14). ${ }^{\left[{ }^{[3]}\right.}$ Similar effects using the Fourier technique have been applied to other gases. ${ }^{[72,92,94,95]}$
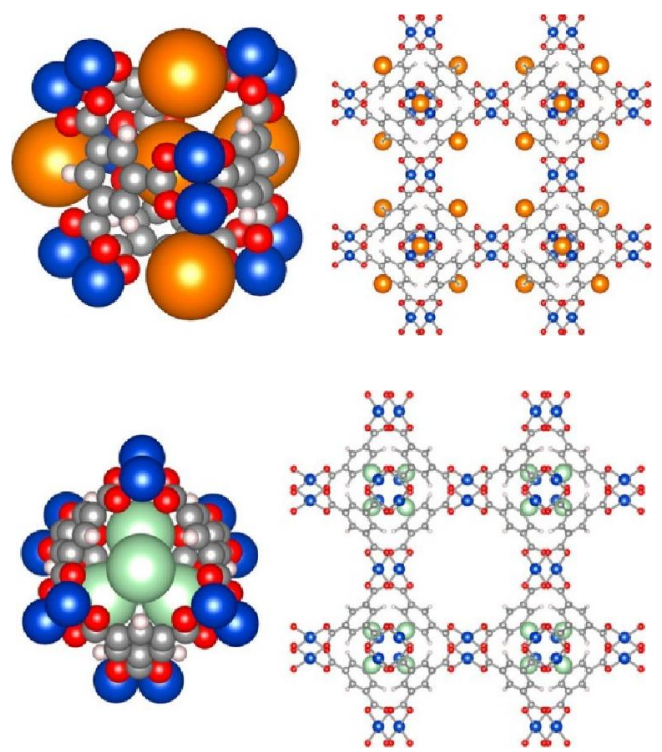

Figure 14 Adsorption sites for (a)Xe (orange atoms) and (b)Ar (green atoms) in HKUST-1 using analysis through synchrotron X-ray and neutron powder diffraction. Reprinted with permission from Ref. [93]. Copyright 2013 American Chemical Society.

\section{X-ray spectroscopy}

As we discussed before, X-rays hit a crystalline sample, it can produce stronger interference signals that uncover structure information of the crystal. In fact, part of X-rays could simultaneously be absorbed and disturb the electronic structure of crystalline materials (including MOF), which can provide direct observation of changes occurring in the crystals at the molecular orbital level. For example, one in situ measurement at the Mg K-edge of Mg-MOF-74 using X-ray spectroscopy demonstrated distinct pre-edge absorption features associated with the unique and open Mg coordination in Mg-MOF-74. ${ }^{[96]}$ The mixing of $\mathrm{Mg} 3 \mathrm{p}$ and $3 \mathrm{~s}$ characters resulted in a strong pre-edge absorption peak for the activated Mg-MOF-74 (Figure 15). However, this signature feature disappeared in the pres- 


\section{General Chemistry}

ence of $\mathrm{CO}_{2}$, which was the proof of coordination of $\mathrm{CO}_{2}$ to the open metal sites. Moreover, a blue shift of the pre-edge peak with an increased intensity was noted after introducing $\mathrm{CO}_{2}$ to Mg-MOF-74.

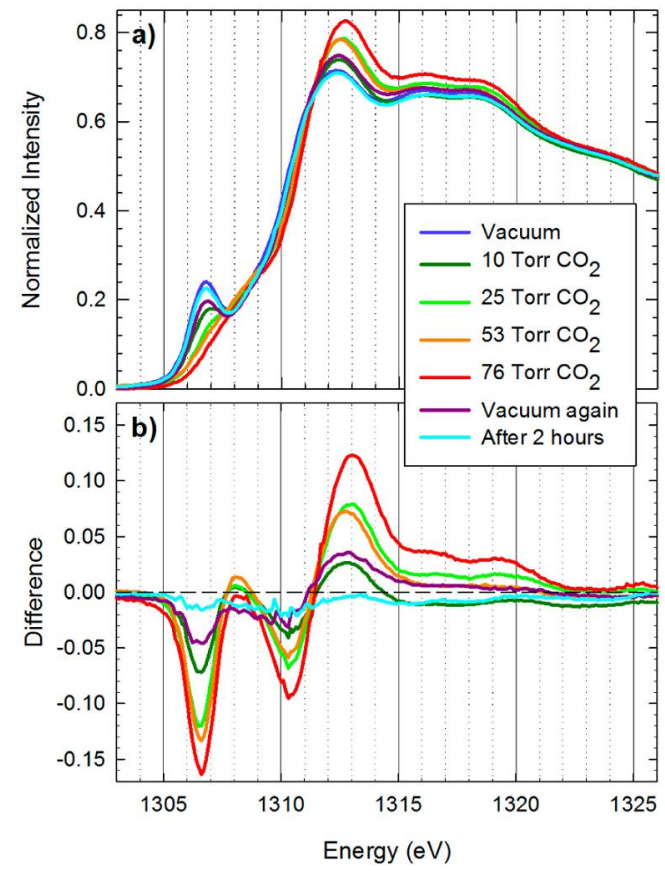

Figure 15 (a) Mg K-edge spectra of Mg-MOF-74 under vacuum, with increasing gas pressure. (b) Difference spectra generated by subtracting the initial vacuum spectrum from all subsequent spectra. Reprinted with permission from Ref. [96]. Copyright 2013 American Chemical Society.

\section{Computation simulations}

Experimentally, it would be difficult and time-consuming to address detailed information, which could be critical to the macroscopic properties that underlying adsorption mechanisms in MOFs. Molecular modeling, by comparison, may provide a valuable complement to experimental studies. ${ }^{[97]}$ During the past decades, great efforts have been made to apply all kinds of computational approaches to investigate properties of MOFs, such as quantum chemistry calculation and molecular simulation. ${ }^{\left[{ }^{[8-115]}\right.}$ Furthermore, several advanced methodologies with respect to this class of novel porous materials, have been developed. ${ }^{[116-118]}$ All these information can help to obtain a deeper and more thorough understanding of the features of MOFs. For adsorption, the main contributions of computational studies are determining adsorption sites and revealing adsorption mechanisms in general. ${ }^{[19,120]}$

\section{Determination of adsorption sites}

\section{Hydrogen storage}

Hydrogen storage is one of the earliest research topics in MOFs area. ${ }^{[3,121,122]}$ In 2004, Sagara and coworkers ${ }^{[123]}$ investigated the binding energy of $\mathrm{H}_{2}$ in MOF-5 using quantum chemistry calculations for the first time. Then, Zhong and Yang $^{[124]}$ performed systematic molecular simulations, including Grand Canonical Monte Carlo (GCMC) and molecular dynamics (MD) simulations, on the adsorption and diffusion of $\mathrm{H}_{2}$ in IRMOFs in 2005. The results indicated that metal-oxygen clusters are preferential adsorption sites for $\mathrm{H}_{2}$, and with the increase of pressure the effect of the organic linkers becomes evident. On the basis of these information about adsorption sites, Zhong and Yang ${ }^{[125]}$ further studied the adsorption of $\mathrm{H}_{2}$ in MOFs using a combined GCMC simulation and density functional theory (DFT) calculation. Several locations and orientations of $\mathrm{H}_{2}$ within MOFs were tested around $\mathrm{Cu}_{2}\left(\mathrm{CO}_{2}\right)_{4}$ unit in MOF-505, ${ }^{[126]}$ and the strongest adsorption configuration is observed to locate in the direction of open metal sites, as shown in Figure 16. $\mathrm{H}_{2}$ molecule is inclined to expose the negative lobe of its quadrupole to the $\mathrm{Cu}$ atom. In addition, they further examined the snapshots of the structures of MOF-505 with adsorbed $\mathrm{H}_{2}$ at various pressures. Typical ones shown in Figure 17 illustrated that the sequence of $\mathrm{H}_{2}$ adsorption is as follows: firstly, $\mathrm{H}_{2}$ molecules occupy the center regions of the smaller pores, which formed by six inorganic $\mathrm{Cu}_{2}\left(\mathrm{CO}_{2}\right)_{4}$ units (Figure 17a); then, they begin to be adsorbed at the corners of the larger pores with the increase of pressure (Figure 17b); $\mathrm{H}_{2}$ molecules finally are adsorbed mainly around the organic units with further increasing pressure (Figure 17c).
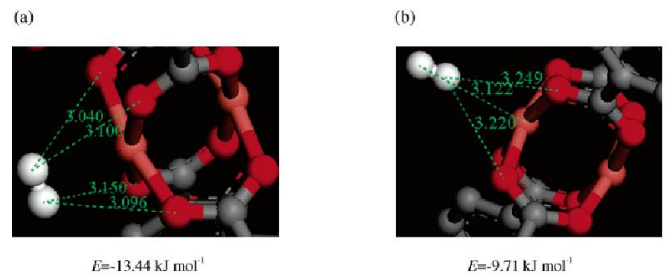

(c)

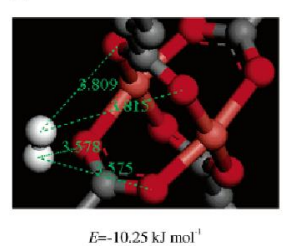

(d)

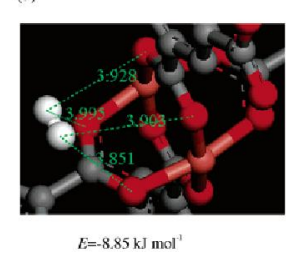

Figure 16 Close-up view of the DFT calculated configurations of an adsorbed molecule around the inorganic $\mathrm{Cu}_{2}\left(\mathrm{CO}_{2}\right)_{4}$ unit in MOF-505. Reprinted with permission from Ref. [125]. Copyright 2006 American Chemical Society.

\section{Methane storage}

Motivated by energy applications, for example, natural gas vehicles, methane adsorption in MOFs have received substantial attention. ${ }^{[3,15,127-129]}$ Zhong and Wang ${ }^{[130]}$ studied the adsorption sites, conformation and the adsorption energies of $\mathrm{CH}_{4}$ in MOF-5 using DFT calculations. Through a systematic structure optimization, the $\mathrm{Zn}_{4} \mathrm{O}$ clusters are identified as the preferential adsorption sites (I, II position in Figure 18), and O-Zn narrow area (I position in Figure 18) shows the largest adsorption energy for $\mathrm{CH}_{4}$. Herein, $\mathrm{C}-\mathrm{H}$ bond in $\mathrm{CH}_{4}$ molecule is in the position of pointing to $\mathrm{O}$ atom in the framework. Zhou and coworkers ${ }^{[92]}$ investigated $\mathrm{CH}_{4}$ adsorption sites in several typical MOFs by performing GCMC simulations in combination with DFT calculation as well as neutron powder diffraction (NPD) method. For example, in HKUST-1, the window site of the small octahedral cage is considered as another primary $\mathrm{CH}_{4}$ adsorption site, besides the open metal site as conventionally known. The distance between an adsorbed $\mathrm{CH}_{4}$ molecule and $\mathrm{O}$ atoms in framework is in the range of 2.7-3.2 $\AA$, inducing strong interaction of $\mathrm{CH}_{4}$ around these window sites. In PCN-11, it is found that the large cage corner sites also provide major adsorption sites and contribute significantly to a remarkable total $\mathrm{CH}_{4}$ uptake of $194 \mathrm{~cm}^{3}$ (STP) $\mathrm{cm}^{-3}$ at $298 \mathrm{~K}$ and 35 bar.

\section{Carbon dioxide capture}

Compared to $\mathrm{H}_{2}$ and $\mathrm{CH}_{4}$, the adsorption of carbon dioxide molecules in MOFs is more complicated due to their quadrupole moments. ${ }^{[97]}$ By analyzing the center of mass (COM) 


\section{Review}

(a) $P=0.00013 \mathrm{MPa}$
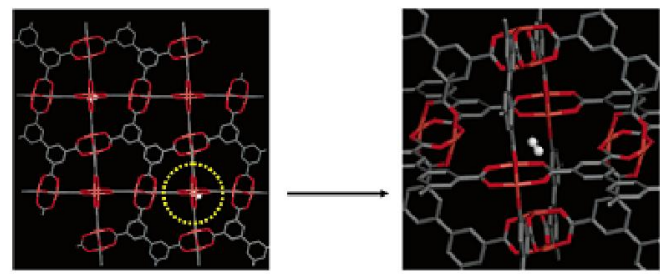

(b) $\mathrm{P}=0,0043 \mathrm{MPa}$
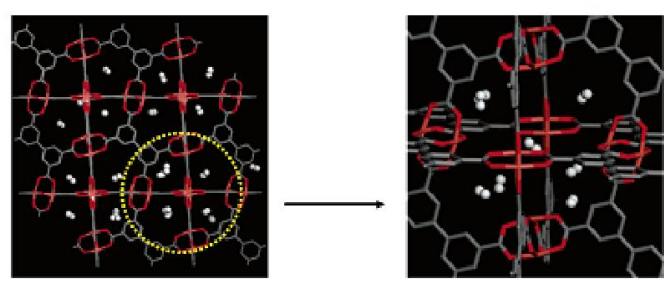

(c) $\mathrm{P}=0.10 \mathrm{MPa}$
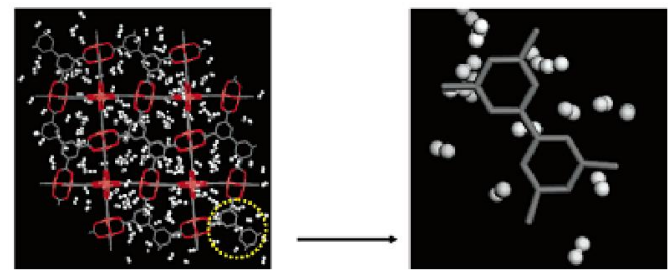

Figure 17 Snapshots of the structures of MOF-505 with adsorbed $\mathrm{H}_{2}$ at various pressures. Reprinted with permission from Ref. [125]. Copyright 2006 American Chemical Society.

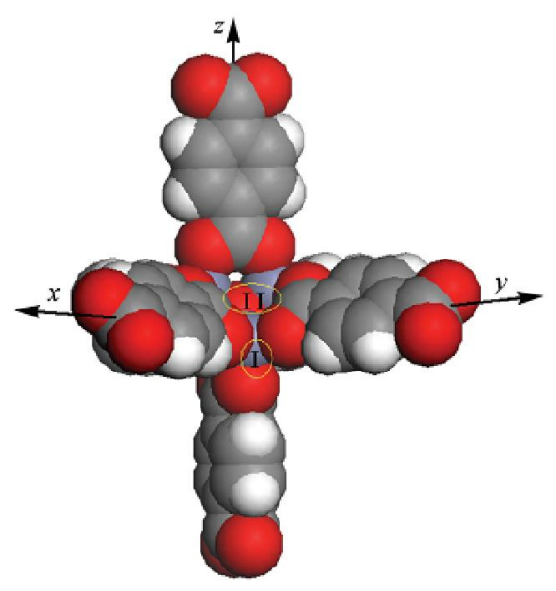

Figure 18 The adsorption sites of $\mathrm{CH}_{4}$ near the $\mathrm{Zn}_{4} \mathrm{O}$ cluster: (I) O-Zn narrow area and (II): O-Zn wide area. Reprinted with permission from ref.[130]. Copyright 2006 Chinese Chemical Society.

probability distributions of $\mathrm{CO}_{2}$ extracted from GCMC simulations carefully, Zhong and coworkers ${ }^{[131]}$ believed the preferential adsorption sites of $\mathrm{CO}_{2}$ in chemical Li-modified MOF-5 (chem-2Li) was different from those in the original material as well as the physical Li-modified one (phys-2Li), attributed mainly to the stronger charge-quadrupole interaction. The statistical results from simulation illustrate that $\mathrm{CO}_{2}$ molecules tend to bridge between two ligands instead of pointing to the metal clusters in phys-2Li. While in chem-2Li the $\mathrm{CO}_{2}$ molecules are not parallel to the O-Li dipoles, the most probable distribution of the angle is about $45^{\circ}$.

\section{Adsorption mechanism}

More recently, considerable efforts has been made to explore the adsorption mechanism fully utilizing the irreplaceable advantage of computational methods. Classical simulations with quadratic Feynman-Hibbs $(\mathrm{FH})$ effective potential indicated that quantum effect plays a significant effect on the $\mathrm{H}_{2}$ adsorption especially at low temperature, due to their unique characters. ${ }^{[132-134]}$ On the basis of this effect, quantum sieving can be used to separate the hydrogen isotope mixtures efficiently, which takes place on the condition that the difference between molecular size and pore size becomes comparable to the de Broglie wavelengths of hydrogen. The difference in the zero point energy (ZPE) induces that heavier isotopes are confined less than lighter ones in the pore. ${ }^{[135]}$ With the aid of various computational tools, it can be predicted that MOFs are suitable candidates for the separation of hydrogen isotopes through quantum sieving, including path integral Monte Carlo, ${ }^{[136]}$ proposed novel concept like "quantum effective pore size" (QEPS). ${ }^{[137]}$ This have been verified by recent direct measurement in experiment. ${ }^{[138]}$ MOF-74, ${ }^{[139]}$ as one of benchmark MOFs with a high density of open metal sites, has received special attention because of their fast and specific $\mathrm{CO}_{2}$ adsorption. Several groups focused on performing calculations to provide insights into the nature of the strong binding of $\mathrm{CO}_{2}$ with the framework and try to understand the adsorption mechanisms, which are critical for the rational design of improved MOFs. ${ }^{[140-142]}$ Thonhauser and coworkers ${ }^{[117]}$ incorporated van der Waals forces self-consistently in DFT in the form of a van der Waals density functional (vdW-DF) to analyze $\mathrm{CO}_{2}$ adsorption in MOF-74. The calculation results indicate fully occupied semi-core $3 d$ electrons in $\mathrm{Zn}$ have a significant effect on the interaction with the adsorbed $\mathrm{CO}_{2}$ molecules. Furthermore, it is found that there is a depletion of electrons around $\mathrm{Zn}$ atom upon adsorbed $\mathrm{CO}_{2}$, while this depletion was not existed for Mg-MOF-74, by applying a charge-density analysis. The depletion of charge is an effect of the $\mathrm{Zn} d$ orbitals that also affects the charge distribution in the adsorbed $\mathrm{CO}_{2}$ molecules. This can be used to explain computational and experimental findings that the binding energy of $\mathrm{CO}_{2}$ molecule in Mg-MOF-74 is larger than that in Zn-MOF-74. ${ }^{[52]}$ Jung and coworkers ${ }^{[141]}$ performed a series of quantum chemistry calculations and predicted that Tiand V-MOF-74 should have an enhanced affinity of $\mathrm{CO}_{2} \mathrm{com}-$ pared to Mg-MOF-74, which may be attributed to the formation of additional weak coordination bonds with $\mathrm{CO}_{2}$ through forward donation. Smit, Gagliardi, and coworkers ${ }^{[143]}$ characterized the reactive adsorption of $\mathrm{CO}_{2}$ in the amine-functionalized $\mathrm{Mg}_{2}$ (dobpdc) by quantum-chemical calculations. It is believed that there is the formation of a hydrogen-bonded complex involving two carbamic acid moieties during the adsorption process, and the proposed mechanism is as shown in Figure 19.

\section{Comprehensive kinetic studies in gas sorption}

Kinetic studies of gas adsorption process can reveal molecular transport/diffusion behaviors inside porous materials, thus help to guide the design of new materials targeting for certain gas storage or separation applications. ${ }^{[144-146]}$ To date, research regarding this topic is still relatively rare, presumably due to the difficulties in observing the transport behaviors of gas molecules with traditional characterization techniques.

In the research of MOFs for methane storage applications, Lucena and coworkers ${ }^{[147]}$ reported firstly a "methane transport" phenomenon in $\mathrm{PCN}-14$. The simulations showed that there was no energy barrier between weak and strong adsorption sites, suggesting the methane molecules are guided from open 


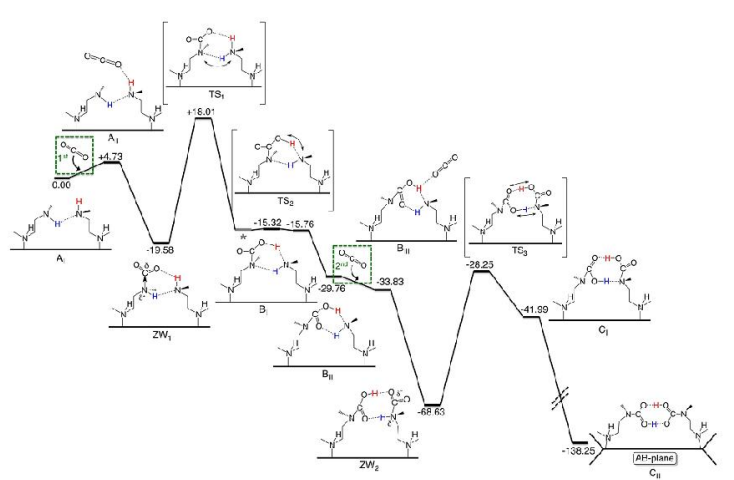

Figure 19 The proposed mechanism of $\mathrm{CO}_{2}$ adsorption in an alkylamine-functionalized $\mathrm{Mg}_{2}$ (dobpdc). (left) First $\mathrm{CO}_{2}$ uptake; (right) second $\mathrm{CO}_{2}$ uptake. Reprinted with permission from Ref. [143]. Copyright 2013 American Chemical Society.

metal sites to other adjacent adsorption sites inside this MOF (Figure 20). This kinetic transport phenomenon of methane molecules inside PCN-14 is very interesting, but it was only confirmed by computational studies in their work. In 2015, the Zhou group ${ }^{[148]}$ did a systematic study on methane storage in several MOFs and discovered similar kinetic behaviors of methane molecules inside these MOFs. Combining three tools: experimental observations, simulations and in situ PXRD technique, they studied gas dynamics and the distribution of guest molecules under various conditions in MOFs. In this study, in situ PXRD characterization technique was utilized to study the kinetic behaviors of gas molecules in MOFs for the first time. Using synchrotron radiation source, the PXRD patterns of MOFs loaded with methane were measured, respectively. The electron density distribution was then obtained from a few reflection peaks in the diffraction pattern of both samples. Structure envelop surface can be generated from the electron density distribution information. ${ }^{[81,82,149,150]}$ Comparison of the structure envelope surfaces in the activated and methane loaded MOFs gives the information of adsorption sites inside the MOFs. By measuring the in situ PXRD of MOFs at different temperatures, they confirmed experimentally the "methane migration" mechanism, which is the methane molecules migrate from open metal sites to "window" structure in the adsorption process. Essentially, in situ PXRD detects the electron density difference in activated sample and gas loaded sample at a certain temperature or time. Using this method to detect the gas adsorption sites at different temperatures or time gives insight into the kinetic information in gas adsorption process (Figure 21).

Combining simulation and in situ characterization, Canepa and coworkers ${ }^{[140]}$ studied the transport mechanism of small molecules in Mg-MOF-74. Simulation was firstly employed to predict the diffusion behaviors of gas molecules in the MOF. Instead of in situ PXRD, they used time-resolved in situ IR, which measures the changes in asymmetric modes of gas molecules. The asymmetric stretch modes of $\mathrm{CO}_{2}$ and $\mathrm{H}_{2} \mathrm{O}$, which was obtained from in situ IR spectroscopy, indicate two consecutive steps involved in a typical gas loading process of Mg-MOF-74. The gas molecules were firstly adsorbed in nanopores on the surface of the MOF, resulting in a very high loading in those nanopores thus limiting diffusion of more approaching molecules. The increasing lateral interactions between adsorbed molecules could lead to a redshift, which was observed from in situ IR. As time progresses, the in situ IR showed a blueshift indicating the asymmetric modes went back to its original location. Accordingly, this change indicated the diffusion of the gas molecules from high-loaded pores to low-
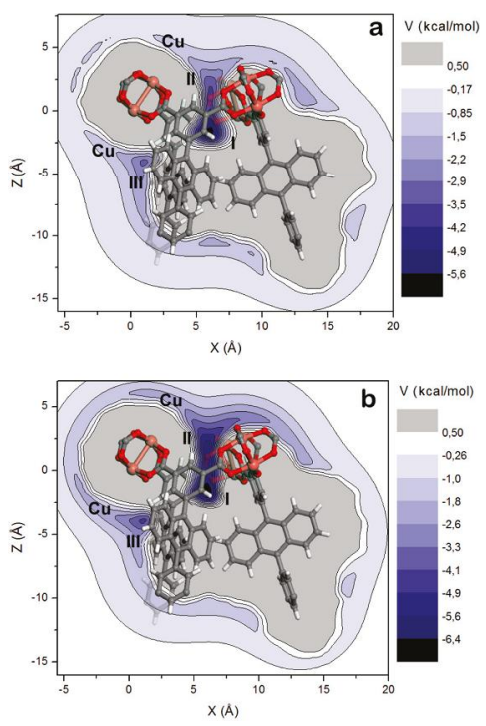

Figure 20 (a) Contour plot of the calculated potential energy of methane molecules in the $x z$ plane that goes from the copper atoms of a $\mathrm{Cu}_{2}\left(\mathrm{CO}_{2}\right) 4$ cluster, crossing the center of the basket partial structure. $\varepsilon_{\mathrm{Cu}}=0.006 \mathrm{kcal} / \mathrm{mol}$. (b) Contour plot of the potential energy for $\varepsilon_{\mathrm{cu}}=3.81 \mathrm{kcal} / \mathrm{mol}$. Reprinted with the permission from Ref. [147]. Copyright 2011 American Chemical Society.

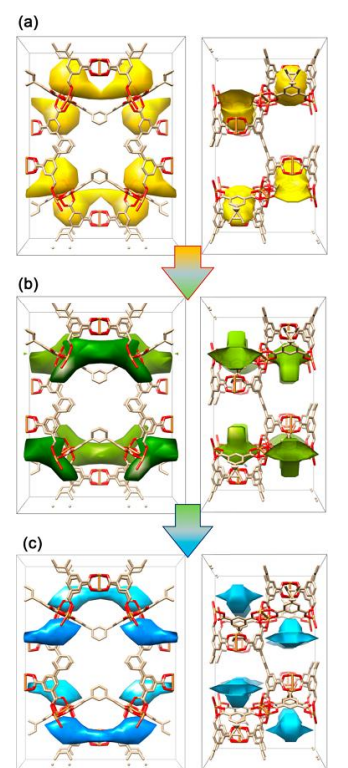

Figure 21 DED snapshots illustrate the evolution of $\mathrm{CH}_{4}$ equilibrium states in $\mathrm{PCN}-306$. The $\mathrm{CH}_{4}$-loaded crystals were diffracted at (a) $295 \mathrm{~K}$, (b) $200 \mathrm{~K}$, and (c) $150 \mathrm{~K}$. The right-side images, viewed along the a-axis. Reprinted with the permission from Ref. [148]. Copyright 2015 American Chemical Society.

loading pores that located further inside the MOF. The frequency shifts in in situ IR was a direct evidence of the two-stage mechanism in the gas diffusion process. More of such typical studies could be found in the review paper by Thonhauser and coworkers. $^{[117]}$

\section{Conclusions}

Gas storage and separations, including methane, carbon dioxide and hydrogen, are very important for people's existence 


\section{Review}

and development. The discovery of materials with high gas storage capacity or outstanding separation capacity has been a hot and challenging topic. ${ }^{[151,152]}$ As a kind of typical porous material, MOFs, one of the candidates for gas storage and separations, catch people's eyes. ${ }^{[153,154]}$ However, when it comes down to the real application, the investigation of MOFs as potential sorbents for gas storage presents significant challenges from raw to ready. Therefore, a prospective approach to address this difference is to establish the adsorption process with various methods simultaneously and cooperatively. Fortunately, the aforementioned studies have demonstrated the convenience and precision in determining the adsorption sites and showcase the importance of the metal units, organic linkers, the pore size, and the gas molecule itself with the help of different characterization methods. Integration of the knowledge gained from those methods will certainly promote an insight about the gas sorption process and definitely be tailored to the design of new generation of MOFs. In brief, we believe that a successful implementation in the application of MOFs as gas sorbents lies heavily on the understanding of routine gas sorption process, and such studies will continue to not only make contributions to the application of MOFs but also drive the development of individual technologies to new frontiers.

\section{Acknowledgement}

T. F. L. thanks "Strategic Priority Research Program" of Chinese Academy of Sciences (No. XDB20000000) for supports.

\section{Author Contributions}

${ }^{\dagger}$ X.-J. H. and X. W. contributed equally to this work.

\section{References}

[1] Li, B.; Chrzanowski, M.; Zhang, Y.; Ma, S. Coord. Chem. Rev. 2016, 307, 106.

[2] Helal, A.; Yamani, Z. H.; Cordova, K. E.; Yaghi, O. M. Natl. Sci. Rev. 2017, 4, 296.

[3] Li, H.; Wang, K.; Sun, Y.; Lollar, C. T.; Li, J.; Zhou, H.-C. Mater. Today 2018, 21, 108.

[4] Hoskins, B. F.; Robson, R. J. Am. Chem. Soc. 1990, 112, 1546.

[5] Makal, T. A.; Li, J. R.; Lu, W.; Zhou, H. C. Chem. Soc. Rev. 2012, 41, 7761.

[6] Xu, G.; Gang, F.; Dong, T.; Fu, Y.; Du, Z. Chin. J. Chem. 2016, 36, 1513.

[7] Yuan, S.; Feng, L.; Wang, K.; Pang, J.; Bosch, M.; Lollar, C.; Sun, Y.; Qin, J.; Yang, X.; Zhang, P.; Wang, Q.; Zou, L.; Zhang, Y.; Zhang, L.; Fang, Y.; Li, J.; Zhou, H. C. Adv. Mater. 2018, 1704303.

[8] Eddaoudi, M.; Kim, J.; Rosi, N.; Vodak, D.; Wachter, J.; O'Keeffe, M.; Yaghi, O. M. Science 2002, 295, 469.

[9] Collins, D. J.; Zhou, H.-C. J. Mater. Chem. 2007, 17, 3154.

[10] Zhao, D.; Yuan, D.; Zhou, H.-C. Energy Environ. Sci. 2008, 1, 222.

[11] Murray, L. J.; Dinca, M.; Long, J. R. Chem. Soc. Rev. 2009, 38, 1294.

[12] Langmi, H. W.; Ren, J.; North, B.; Mathe, M.; Bessarabov, D. Electrochim. Acta 2014, 128, 368.

[13] Peng, Y.; Krungleviciute, V.; Eryazici, I.; Hupp, J. T.; Farha, O. K.; Yildirim, T. J. Am. Chem. Soc. 2013, 135, 11887.

[14] Konstas, K.; Osl, T.; Yang, Y.; Batten, M.; Burke, N.; Hill, A. J.; Hill, M. R. J. Mater. Chem. 2012, 22, 16698.

[15] He, Y.; Zhou, W.; Qian, G.; Chen, B. Chem. Soc. Rev. 2014, 43, 5657.

[16] Mason, J. A.; Veenstra, M.; Long, J. R. Chem. Sci. 2014, 5, 32.

[17] Li, B.; Wen, H.-M.; Wang, H.; Wu, H.; Yildirim, T.; Zhou, W.; Chen,
B. Energy Environ. Sci. 2015, 8, 2504.

[18] Ferey, G.; Serre, C.; Devic, T.; Maurin, G.; Jobic, H.; Llewellyn, P. L.; De Weireld, G.; Vimont, A.; Daturi, M.; Chang, J.-S. Chem. Soc. Rev. 2011, 40, 550.

[19] Li, J.-R.; Sculley, J.; Zhou, H.-C. Chem. Rev. 2011, 112, 869.

[20] Sumida, K.; Rogow, D. L.; Mason, J. A.; McDonald, T. M.; Bloch, E. D.; Herm, Z. R.; Bae, T.-H.; Long, J. R. Chem. Rev. 2011, 112, 724.

[21] Liu, Y.; Wang, Z. U.; Zhou, H.-C. Greenhouse Gas Sci. Technol. 2012, 2, 239.

[22] Scott, H. S.; Ogiwara, N.; Chen, K.-J.; Madden, D. G.; Pham, T.; Forrest, K.; Space, B.; Horike, S.; Perry, J. J.; Kitagawa, S.; Zaworotko, M. J. Chem. Sci. 2016, 7, 5470.

[23] [23] Siegelman, R. L.; McDonald, T. M.; Gonzalez, M. I.; Martell, J. D.; Milner, P. J.; Mason, J. A.; Berger, A. H.; Bhown, A. S.; Long, J. R. J. Am. Chem. Soc. 2017, 139, 10526.

[24] Chui, S. S.-Y.; Lo, S. M.-F.; Charmant, J. P. H.; Orpen, A. G.; Williams, I. D. Science 1999, 283, 1148.

[25] Krause, S.; Bon, V.; Senkovska, I.; Stoeck, U.; Wallacher, D. Tobbens, D. M.; Zander, S.; Pillai, R. S.; Maurin, G.; Coudert, F. X.; Kaskel, S. Nature 2016, 532, 348.

[26] Cho, H. S.; Deng, H.; Miyasaka, K.; Dong, Z.; Cho, M.; Neimark, A V.; Kang, J. K.; Yaghi, O. M.; Terasaki, O. Nature 2015, 527, 503.

[27] Lamberti, C.; Zecchina, A.; Groppo, E.; Bordiga, S. Chem. Soc. Rev. 2010, 39, 4951.

[28] Tan, K.; Jensen, S.; Zuluaga, S.; Chapman, E. K.; Wang, H.; Rahman, R.; Cure, J.; Kim, T.-H.; Li, J.; Thonhauser, T.; Chabal, Y. J. J. Am. Chem. Soc. 2018, 140, 856.

[29] Nijem, N.; Veyan, J.-F.; Kong, L.; Li, K.; Pramanik, S.; Zhao, Y.; Li, J.; Langreth, D.; Chabal, Y. J. J. Am. Chem. Soc. 2010, 132, 1654.

[30] Nijem, N.; Veyan, J.-F.; Kong, L.; Wu, H.; Zhao, Y.; Li, J.; Langreth, D. C.; Chabal, Y. J. J. Am. Chem. Soc. 2010, 132, 14834.

[31] FitzGerald, S. A.; Burkholder, B.; Friedman, M.; Hopkins, J. B.; Pierce, C. J.; Schloss, J. M.; Thompson, B.; Rowsell, J. L. C. J. Am. Chem. Soc. 2011, 133, 20310.

[32] Tan, K.; Canepa, P.; Gong, Q.; Liu, J.; Johnson, D. H.; Dyevoich, A.; Thallapally, P. K.; Thonhauser, T.; Li, J.; Chabal, Y. J. Chem. Mater. 2013, 25, 4653.

[33] Nijem, N.; Canepa, P.; Kaipa, U.; Tan, K.; Roodenko, K.; Tekarli, S.; Halbert, J.; Oswald, I. W. H.; Arvapally, R. K.; Yang, C.; Thonhauser, T.; Omary, M. A.; Chabal, Y. J. J. Am. Chem. Soc. 2013, 135, 12615.

[34] Bordiga, S.; Regli, L.; Bonino, F.; Groppo, E.; Lamberti, C.; Xiao, B.; Wheatley, P. S.; Morris, R. E.; Zecchina, A. Phys. Chem. Chem. Phys. 2007, 9, 2676.

[35] Bloch, E. D.; Hudson, M. R.; Mason, J. A.; Chavan, S.; Crocella, V.; Howe, J. D.; Lee, K.; Dzubak, A. L.; Queen, W. L.; Zadrozny, J. M. Geier, S. J.; Lin, L.-C.; Gagliardi, L.; Smit, B.; Neaton, J. B.; Bordiga, S.; Brown, C. M.; Long, J. R. J. Am. Chem. Soc. 2014, 136, 10752.

[36] Reed, D. A.; Xiao, D. J.; Gonzalez, M. I.; Darago, L. E.; Herm, Z. R.; Grandjean, F.; Long, J. R. J. Am. Chem. Soc. 2016, 138, 5594

[37] Sato, H.; Kosaka, W.; Matsuda, R.; Hori, A.; Hijikata, Y.; Belosludov, R. V.; Sakaki, S.; Takata, M.; Kitagawa, S. Science 2014, 343, 167.

[38] Vimont, A.; Travert, A.; Bazin, P.; Lavalley, J.-C.; Daturi, M.; Serre, C.; Ferey, G.; Bourrelly, S.; Llewellyn, P. L. Chem. Commun. 2007, 3291.

[39] Stavitski, E.; Pidko, E. A.; Couck, S.; Remy, T.; Hensen, E. J. M.; Weckhuysen, B. M.; Denayer, J.; Gascon, J.; Kapteijn, F. Langmuir 2011, 27, 3970.

[40] McDonald, T. M.; Mason, J. A.; Kong, X. Q.; Bloch, E. D.; Gygi, D.; Dani, A.; Crocella, V.; Giordanino, F.; Odoh, S. O.; Drisdell, W. S.; Vlaisavljevich, B.; Dzubak, A. L.; Poloni, R.; Schnell, S. K.; Planas, N.; Lee, K.; Pascal, T.; Wan, L. W. F.; Prendergast, D.; Neaton, J. B.; Smit, B.; Kortright, J. B.; Gagliardi, L.; Bordiga, S.; Reimer, J. A.; Long, J. R. Nature 2015, 519, 303.

[41] Krap, C. P.; Newby, R.; Dhakshinamoorthy, A.; Garcia, H.; Cebula 


\section{General Chemistry}

I.; Easun, T. L.; Savage, M.; Eyley, J. E.; Gao, S.; Blake, A. J.; Lewis, W.; Beton, P. H.; Warren, M. R.; Allan, D. R.; Frogley, M. D.; Tang, C. C.; Cinque, G.; Yang, S.; Schroeder, M. Inorg. Chem. 2016, 55, 1076.

[42] Savage, M.; Cheng, Y.; Easun, T. L.; Eyley, J. E.; Argent, S. P.; Warren, M. R.; Lewis, W.; Murray, C.; Tang, C. C.; Frogley, M. D.; Cinque, G.; Sun, J.; Rudic, S.; Murder, R. T.; Benham, M. J.; Fitch, A. N.; Blake, A. J.; Ramirez-Cuesta, A. J.; Yang, S.; Schroder, M. Adv. Mater. 2016, 28, 8705.

[43] Lin, L.-C.; Kim, J.; Kong, X.; Scott, E.; McDonald, T. M.; Long, J. R.; Reimer, J. A.; Smit, B. Angew. Chem. Int. Ed. 2013, 52, 4410-4413.

[44] Dobrowolski, J. C.; Jamróz, M. H. J. Mater. Chem. 1992, 275, 211.

[45] Hanson, R. C.; Jones, L. H. J. Chem. Phys. 1981, 75, 1102.

[46] Serre, C.; Bourrelly, S.; Vimont, A.; Ramsahye, N. A.; Maurin, G.; Llewellyn, P. L.; Daturi, M.; Filinchuk, Y.; Leynaud, O.; Barnes, P.; Férey, G. Adv. Mater. 2007, 19, 2246.

[47] Li, J. R.; Sculley, J.; Zhou, H. C. Chem. Rev. 2012, 112, 869.

[48] Sculley, J. P.; Li, J.-R.; Park, J.; Lu, W.; Zhou, H.-C. J. Sustainable Technologies, Systems \& Policies 2012, 16.

[49] Zhang, J.; Zhang, S.; Dong, K.; Zhang, Y.; Shen, Y.; Lv, X. Chem. Eur. J. 2006, 12, 4021.

[50] Devic, T.; Salles, F.; Bourrelly, S.; Moulin, B.; Maurin, G.; Horcajada, P.; Serre, C.; Vimont, A.; Lavalley, J.-C.; Leclerc, H.; Clet, G.; Daturi, M.; Llewellyn, P. L.; Filinchuk, Y.; Ferey, G. J. Mater. Chem. 2012, 22, 10266.

[51] Dietzel, P. D. C.; Johnsen, R. E.; Fjellvag, H.; Bordiga, S.; Groppo, E.; Chavan, S.; Blom, R. Chem. Commun. 2008, 5125.

[52] Yao, Y.; Nijem, N.; Li, J.; Chabal, Y. J.; Langreth, D. C.; Thonhauser, T. Phys. Rev. B 2012, 85, 064302.

[53] Tan, K.; Nijem, N.; Canepa, P.; Gong, Q.; Li, J.; Thonhauser, T.; Chabal, Y. J. Chem. Mater. 2012, 24, 3153.

[54] Zhang, J.-P.; Liao, P.-Q.; Zhou, H.-L.; Lin, R.-B.; Chen, X.-M. Chem. Soc. Rev. 2014, 43, 5789.

[55] Liao, P.-Q.; Huang, N.-Y.; Zhang, W.-X.; Zhang, J.-P.; Chen, X.-M. Science 2017, 356, 1193

[56] Banerjee, D.; Simon, C. M.; Plonka, A. M.; Motkuri, R. K.; Liu, J.; Chen, X.; Smit, B.; Parise, J. B.; Haranczyk, M.; Thallapally, P. K. Nat. Commun. 2016, 7, 11831.

[57] Bachman, J. E.; Kapelewski, M. T.; Reed, D. A.; Gonzalez, M. I.; Long, J. R. J. Am. Chem. Soc. 2017, 139, 15363.

[58] Maji, T. K.; Mostafa, G.; Matsuda, R.; Kitagawa, S. J. Am. Chem. Soc. 2005, 127, 17152

[59] Graham, A. J.; Banu, A.-M.; Düren, T.; Greenaway, A.; McKellar, S. C.; Mowat, J. P. S.; Ward, K.; Wright, P. A.; Moggach, S. A. J. Am. Chem. Soc. 2014, 136, 8606.

[60] Takamizawa, S.; Nataka, E.-i.; Akatsuka, T.; Miyake, R.; Kakizaki, Y.; Takeuchi, H.; Maruta, G.; Takeda, S. J. Am. Chem. Soc. 2010, 132, 3783.

[61] Allan, P. K.; Xiao, B.; Teat, S. J.; Knight, J. W.; Morris, R. E. J. Am. Chem. Soc. 2010, 132, 3605.

[62] Miller, S. R.; Wright, P. A.; Devic, T.; Serre, C.; Férey, G.; Llewellyn, P. L.; Denoyel, R.; Gaberova, L.; Filinchuk, Y. Langmuir 2009, 25, 3618.

[63] Carrington, E. J.; Vitorica-Yrezabal, I. J.; Brammer, L. Acta Crystallogr., Sect. B: Struct. Sci 2014, 70, 404.

[64] Lyndon, R.; Konstas, K.; Evans, R. A.; Keddie, D. J.; Hill, M. R.; Ladewig, B. P. Adv. Funct. Mater. 2015, 25, 4405.

[65] Zheng, J.; Vemuri, R. S.; Estevez, L.; Koech, P. K.; Varga, T.; Camaioni, D. M.; Blake, T. A.; McGrail, B. P.; Motkuri, R. K. J. Am. Chem. Soc. 2017, 10601.

[66] Flaig, R. W.; Osborn Popp, T. M.; Fracaroli, A. M.; Kapustin, E. A.; Kalmutzki, M. J.; Altamimi, R. M.; Fathieh, F.; Reimer, J. A.; Yaghi, O. M. J. Am. Chem. Soc. 2017, 139, 12125.

[67] Milner, P. J.; Siegelman, R. L.; Forse, A. C.; Gonzalez, M. I.; Runcevski, T.; Martell, J. D.; Reimer, J. A.; Long, J. R. J. Am. Chem. Soc. 2017, 139, 13541.

[68] Zhang, J.-P.; Chen, X.-M. J. Am. Chem. Soc. 2009, 131, 5516.
[69] Lin, J.-B.; Xue, W.; Zhang, J.-P.; Chen, X.-M. Chem. Commun. 2011, 47, 926

[70] Vaidhyanathan, R.; Iremonger, S. S.; Shimizu, G. K. H.; Boyd, P. G.; Alavi, S.; Woo, T. K. Science 2010, 330, 650.

[71] Liao, P.-Q.; Zhou, D.-D.; Zhu, A.-X.; Jiang, L.; Lin, R.-B.; Zhang, J.-P.; Chen, X.-M. J. Am. Chem. Soc. 2012, 134, 17380.

[72] Yang, S.; Sun, J.; Ramirez-Cuesta, A. J.; Callear, S. K.; David, W. I.; Anderson, D. P.; Newby, R.; Blake, A. J.; Parker, J. E.; Tang, C. C.; Schroder, M. Nat. Chem. 2012, 4, 887.

[73] Bureekaew, S.; Sato, H.; Matsuda, R.; Kubota, Y.; Hirose, R.; Kim, J.; Kato, K.; Takata, M.; Kitagawa, S. Angew. Chem. Int. Ed. 2010, 49, 7660.

[74] Bon, V.; Senkovska, I.; Wallacher, D.; Heerwig, A.; Klein, N.; Zizak, I.; Feyerherm, R.; Dudzik, E.; Kaskel, S. Microporous Mesoporous Mater. 2014, 188, 190.

[75] Llewellyn, P. L.; Bourrelly, S.; Serre, C.; Filinchuk, Y.; Férey, G. Angew. Chem. Int. Ed. 2006, 45, 7751

[76] Llewellyn, P. L.; Horcajada, P.; Maurin, G.; Devic, T.; Rosenbach, N.; Bourrelly, S.; Serre, C.; Vincent, D.; Loera-Serna, S.; Filinchuk, Y.; Férey, G. J. Am. Chem. Soc. 2009, 131, 13002.

[77] Devic, T.; Salles, F.; Bourrelly, S.; Moulin, B.; Maurin, G.; Horcajada, P.; Serre, C.; Vimont, A.; Lavalley, J.-C.; Leclerc, H.; Clet, G.; Daturi, M.; Llewellyn, P. L.; Filinchuk, Y.; Férey, G. J. Mater. Chem. 2012, 22, 10266

[78] Llewellyn, P. L.; Maurin, G.; Devic, T.; Loera-Serna, S.; Rosenbach, N.; Serre, C.; Bourrelly, S.; Horcajada, P.; Filinchuk, Y.; Férey, G. J. Am. Chem. Soc. 2008, 130, 12808.

[79] Park, J.; Yuan, D.; Pham, K. T.; Li, J. R.; Yakovenko, A.; Zhou, H. C. J. Am. Chem. Soc. 2012, 134, 99.

[80] Yakovenko, A. A.; Reibenspies, J. H.; Bhuvanesh, N.; Zhou, H.-C. J. Appl. Crystallogr. 2013, 46, 346.

[81] Brenner, S.; McCusker, L. B.; Baerlocher, C. J. Appl. Crystallogr. 2002, 35, 243.

[82] Brenner, S.; McCusker, L. B.; Baerlocher, C. J. Appl. Crystallogr. 1997, 30, 1167.

[83] Lin, R.-B.; Li, L.; Wu, H.; Arman, H.; Li, B.; Lin, R.-G.; Zhou, W.; Chen, B. J. Am. Chem. Soc. 2017, 139, 8022.

[84] Spencer, E. C.; Howard, J. A. K.; McIntyre, G. J.; Rowsell, J. L. C.; Yaghi, O. M. Chem. Commun. 2006, 278.

[85] Peterson, V. K.; Liu, Y.; Brown, C. M.; Kepert, C. J. J. Am. Chem. Soc. 2006, 128, 15578.

[86] Peterson, V. K.; Brown, C. M.; Liu, Y.; Kepert, C. J. J. Phys. Chem. B 2011, 115, 8851.

[87] Yildirim, T.; Hartman, M. Phys. Rev. Lett. 2005, 95, 1.

[88] Wu, H.; Zhou, W.; Yildirim, T. J. Am. Chem. Soc. 2007, 129, 5314.

[89] Moreau, F.; da Silva, I.; Al Smail, N. H.; Easun, T. L.; Savage, M.; Godfrey, H. G. W.; Parker, S. F.; Manuel, P.; Yang, S.; Schroeder, M. Nat. Commun. 2017, 8, 14085

[90] Wu, H.; Zhou, W.; Yildirim, T. J. Am. Chem. Soc. 2009, 131, 4995.

[91] Wu, H.; Zhou, W.; Yildirim, T. J. Phys. Chem. C 2009, 113, 3029.

[92] Wu, H.; Simmons, J. M.; Srinivas, G.; Zhou, W.; Yildirim, T. J. Phys. Chem. Lett 2010, 1, 1946

[93] Hulvey, Z.; Lawler, K. V.; Qiao, Z.; Zhou, J.; Fairen-Jimenez, D.; Snurr, R. Q.; Ushakov, S. V.; Navrotsky, A.; Brown, C. M.; Forster, P. M. J. Phys. Chem. B 2013, 117, 20116.

[94] Xiang, S.; Zhou, W.; Gallegos, J. M.; Liu, Y.; Chen, B. J. Am. Chem. Soc. 2009, 131, 12415.

[95] Wriedt, M.; Sculley, J. P.; Yakovenko, A. A.; Ma, Y.; Halder, G. J.; Balbuena, P. B.; Zhou, H.-C. Angew. Chem. Int. Ed. 2012, 51, 9804.

[96] Drisdell, W. S.; Poloni, R.; McDonald, T. M.; Long, J. R.; Smit, B.; Neaton, J. B.; Prendergast, D.; Kortright, J. B. J. Am. Chem. Soc. 2013, 135, 18183

[97] Hobday, C. L.; Woodall, C. H.; Lennox, M. J.; Frost, M.; Kamenev, K.; Duren, T.; Morrison, C. A.; Moggach, S. A. Nat. Commun. 2018 9, 1429.

[98] Colon, Y. J.; Snurr, R. Q. Chem. Soc. Rev. 2014, 43, 5735. 


\section{Review}

[99] Dubbeldam, D.; Snurr, R. Q. Molecular Simulation 2007, 33, 305.

[100] Duren, T.; Bae, Y.-S.; Snurr, R. Q. Chem. Soc. Rev. 2009, 38, 1237.

[101] Getman, R. B.; Bae, Y.-S.; Wilmer, C. E.; Snurr, R. Q. Chem. Rev. 2011, 112, 703

[102] Han, S. S.; Mendoza-Cortes, J. L.; Goddard lii, W. A. Chem. Soc. Rev. 2009, 38, 1460.

[103] Horcajada, P.; Gref, R.; Baati, T.; Allan, P. K.; Maurin, G.; Couvreur, P.; Férey, G.; Morris, R. E.; Serre, C. Chem. Rev. 2011, 112, 1232.

[104] Jiang, J.; Babarao, R.; Hu, Z. Chem. Soc. Rev. 2011, 40, 3599-3612.

[105] Keskin, S.; Liu, J.; Rankin, R. B.; Johnson, J. K.; Sholl, D. S. Ind. Eng. Chem. Res. 2008, 48, 2355.

[106] Krishna, R. Chem. Soc. Rev. 2012, 41, 3099.

[107] Li, J.-R.; Ma, Y.; McCarthy, M. C.; Sculley, J.; Yu, J.; Jeong, H.-K.; Balbuena, P. B.; Zhou, H.-C. Coord. Chem. Rev. 2011, 255, 1791.

[108] Liu, D.; Zhong, C. J. Mater. Chem. 2010, 20, 10308.

[109] Lochan, R. C.; Head-Gordon, M. Phys. Chem. Chem. Phys. 2006, 8, 1357.

[110] Mani-Biswas, M.; Cagin, T. Comput. Theor. Chem. 2012, 987, 42.

[111] Meek, S. T.; Greathouse, J. A.; Allendorf, M. D. Adv. Mater. 2011, 23, 249.

[112] Nagaoka, M.; Ohta, Y.; Hitomi, H. Coord. Chem. Rev. 2007, 251, 2522

[113] Sarkisov, L. Adv. Mater. 2012, 24, 3130.

[114] Xiang, Z.; Cao, D.; Lan, J.; Wang, W.; Broom, D. P. Energy Environ. Sci. 2010, 3, 1469.

[115] Benoit, V.; Pillai, R. S.; Orsi, A.; Normand, P.; Jobic, H.; Nouar, F.; Billemont, P.; Bloch, E.; Bourrelly, S.; Devic, T.; Wright, P. A.; de Weireld, G.; Serre, C.; Maurin, G.; Llewellyn, P. L. J. Mater. Chem. A 2016, 4, 1383

[116] Yang, Q.; Liu, D.; Zhong, C.; Li, J.-R. Chem. Rev. 2013, 113, 8261.

[117] Zuluaga, S.; Canepa, P.; Tan, K.; Chabal, Y. J.; Thonhauser, T. J. Phys.: Condens. Matter 2014, 26, 133002.

[118] Gong, J.; Li, W.; Li, S. Chin. J. Chem. Phys. 2018, 31, 52.

[119] Zhang, W.; Ma, Y.; Santos-Lopez, I. A.; Lownsbury, J. M.; Yu, H.; Liu, W.-G.; Truhlar, D. G.; Campbell, C. T.; Vilches, O. E. J. Am. Chem. Soc. 2018, 140, 328

[120] Wittmann, T.; Mondal, A.; Tschense, C. B. L.; Wittmann, J. J.; Klimm, O.; Siegel, R.; Corzilius, B.; Weber, B.; Kaupp, M.; Senker, J. J. Am. Chem. Soc. 2018, 140, 2135.

[121] Rosi, N. L.; Eckert, J.; Eddaoudi, M.; Vodak, D. T.; Kim, J.; O'Keeffe, M.; Yaghi, O. M. Science 2003, 300, 1127

[122] Ahmed, A.; Liu, Y.; Purewal, J.; Tran, L. D.; Wong-Foy, A. G.; Veenstra, M.; Matzger, A. J.; Siegel, D. J. Energy Environ. Sci. 2017, 10, 2459.

[123] Sagara, T.; Klassen, J.; Ganz, E. J. Chem. Phys. 2004, 121, 12543.

[124] Yang, Q.; Zhong, C. J. Phys. Chem. B 2005, 109, 11862.

[125] Yang, Q.; Zhong, C. J. Phys. Chem. B 2005, 110, 655.

[126] Chen, B.; Ockwig, N. W.; Millward, A. R.; Contreras, D. S.; Yaghi, O. M. Angew. Chem. Int. Ed. 2005, 44, 4745

[127] Wen, H.-M.; Li, B.; Li, L.; Lin, R.-B.; Zhou, W.; Qian, G.; Chen, B. Adv. Mater. 2018, 30, 1704792.

[128] Zhang, Y.; Lucier, B.; Fischer, M.; Gan, Z.; Boyle, P.; Desveaux, B.; Huang, Y. Chem. Eur. J. 2018, 24, 1.

[129] Tian, T.; Zeng, Z.; Vulpe, D.; Casco, M. E.; Divitini, G.; Midgley, P. A.; Silvestre-Albero, J.; Tan, J.-C.; Moghadam, P. Z.; FairenJimenez, D. Nat. Mater. 2018, 17, 174.

[130] Wang, S. Y.; Zhong, C. L. Acta Chim. Sinica 2006, 64, 2375.

[131] Xu, Q.; Liu, D.; Yang, Q.; Zhong, C.; Mi, J. J. Mater. Chem. 2010, 20, 706.

[132] Garberoglio, G.; Skoulidas, A. I.; Johnson, J. K. J. Phys. Chem. B 2005, 109, 13094

[133] Noguchi, D.; Tanaka, H.; Kondo, A.; Kajiro, H.; Noguchi, H.; Ohba, T.; Kanoh, H.; Kaneko, K. J. Am. Chem. Soc. 2008, 130, 6367.
[134] Xu, Q.; Liu, D.; Yang, Q.; Zhong, C. Mol. Simulat. 2009, 35, 748.

[135] Beenakker, J. J. M.; Borman, V. D.; Krylov, S. Y. Chem. Phys. Lett. 1995, 232, 379.

[136] Garberoglio, G. Chem. Phys. Lett. 2009, 467, 270.

[137] Liu, D.; Wang, W.; Mi, J.; Zhong, C.; Yang, Q.; Wu, D. Ind. Eng Chem. Res. 2011, 51, 434

[138] Oh, H.; Savchenko, I.; Mavrandonakis, A.; Heine, T.; Hirscher, M. ACS Nano 2013, 8, 761.

[139] Rosi, N. L.; Kim, J.; Eddaoudi, M.; Chen, B.; O'Keeffe, M.; Yaghi, O. M. J. Am. Chem. Soc. 2005, 127, 1504.

[140] Canepa, P.; Arter, C. A.; Conwill, E. M.; Johnson, D. H.; Shoemaker, B. A.; Soliman, K. Z.; Thonhauser, T. J. Mater. Chem. 2013, 1, 13597.

[141] Park, J.; Kim, H.; Han, S. S.; Jung, Y.|J. Phys. Chem. Lett 2012, 3 , 826

[142] Yu, D.; Yazaydin, A. O.; Lane, J. R.; Dietzel, P. D. C.; Snurr, R. Q. Chem. Sci. 2013, 4, 3544

[143] Planas, N.; Dzubak, A. L.; Poloni, R.; Lin, L.-C.; McManus, A.; McDonald, T. M.; Neaton, J. B.; Long, J. R.; Smit, B.; Gagliardi, L. J. Am. Chem. Soc. 2013, 135, 7402.

[144] Pillai, R. S.; Jobic, H.; Koza, M. M.; Nouar, F.; Serre, C.; Maurin, G.; Ramsahye, N. A. ChemPhysChem 2017, 18, 2739.

[145] Huang, H.; Sato, H.; Aida, T. J. Am. Chem. Soc. 2017, 139, 8784.

[146] Forse, A. C.; Gonzalez, M. I.; Siegelman, R. L.; Witherspoon, V. J.; Jawahery, S.; Mercado, R.; Milner, P. J.; Martell, J. D.; Smit, B.; Bluemich, B.; Long, J. R.; Reimer, J. A. J. Am. Chem. Soc. 2018 140, 1663.

[147] Lucena, S. M. P.; Mileo, P. G. M.; Silvino, P. F. G.; Cavalcante, C. L. J. Am. Chem. Soc. 2011, 133, 19282.

[148] Chen, Y. P.; Liu, Y.; Liu, D.; Bosch, M.; Zhou, H. C. J. Am. Chem. Soc. 2015, 137, 2919.

[149] Schnering, H. G.; Nesper, R. Z. Phys. B: Condens. Matte 1991, 83 407.

[150] Yakovenko, A. A.; Reibenspies, J. H.; Bhuvanesh, N.; Zhou, H.-C J. Appl. Crystallogr. 2013, 46, 346.

[151] Yu, J.; Xie, L.-H.; Li, J.-R.; Ma, Y.; Seminario, J. M.; Balbuena, P. B. Chem. Rev. 2017, 117, 9674

[152] Trickett, C. A.; Helal, A.; Al-Maythalony, B. A.; Yamani, Z. H.; Cordova, K. E.; Yaghi, O. M. Nat. Rev. Mater. 2017, 2, 17045.

[153] Duan, J.; Jin, W.; Kitagawa, S. Coord. Chem. Rev. 2017, 332, 48.

[154] Lin, Y.; Kong, C.; Zhang, Q.; Chen, L. Adv. Energy Mater. 2017, 7, 1601296. 